\title{
CONÓN ENTRE PERSIA Y ATENAS (394-391 A.C.)
}

\section{César Fornis}

\section{Presses Universitaires de Franche-Comté | « Dialogues d'histoire ancienne »}

2008/2 34/2 | pages 33 à 64

ISSN 0755-7256

ISBN 9782848672465

Article disponible en ligne à l'adresse :

http://www.cairn.info/revue-dialogues-d-histoire-ancienne-2008-2-page-33.htm

\section{Pour citer cet article :}

César Fornis, " Conón entre Persia y Atenas (394-391 a.C.) 》, Dialogues d'histoire ancienne 2008/2 (34/2), p. 33-64.

DOI 10.3917/dha.342.0033

Distribution électronique Cairn.info pour Presses Universitaires de Franche-Comté.

(C) Presses Universitaires de Franche-Comté. Tous droits réservés pour tous pays.

La reproduction ou représentation de cet article, notamment par photocopie, n'est autorisée que dans les limites des conditions générales d'utilisation du site ou, le cas échéant, des conditions générales de la licence souscrite par votre établissement. Toute autre reproduction ou représentation, en tout ou partie, sous quelque forme et de quelque manière que ce soit, est interdite sauf accord préalable et écrit de l'éditeur, en dehors des cas prévus par la législation en vigueur en France. Il est précisé que son stockage dans une base de données est également interdit. 


\section{Conón entre Persia y Atenas (394-39r a.C.)}

Después de combatir en 405 como estratego en la batalla de Egospótamos, donde Lisandro aplastó a la armada ateniense y sentenció la guerra del Peloponeso, Conón de Anaflisto se exilió voluntariamente de su Atenas natal ante el temor de posibles represalias del dêmos, encontrando refugio en la corte de su amigo y protector, el rey chipriota Evágoras de Salamina, vasallo de Artajerjes II ${ }^{1}$. Algunos años más tarde, en 398/7, Conón será nombrado precisamente por el Gran Rey almirante de la flota persa y responsable, junto al sátrapa Farnabazo, de un importante programa de construcción naval en Chipre, Fenicia y Cilicia destinado a arrumbar, o cuando menos frenar, la hegemonía naval lacedemonia en el Egeo y la costa de Asia Menor ${ }^{2}$. Recuperaba así un

* Universidad de Sevilla - cfornis@us.es.

El presente estudio se inscribe en el Proyecto de Investigación HUM 2007-61213.

I Isoc. 5.62; 9.52-55; Lys. 19.36 nos dice que, al igual que su estrecho colaborador Nicofemo, Conón formó una segunda familia en Chipre, donde tenía esposa y un hijo, aunque conservaba la ciudadanía

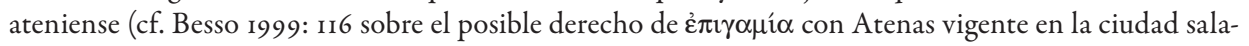
minia). Las fuentes y la literatura moderna sobre Conón hasta el momento de su publicación aparecen en Hofstetter 1978: $\mathrm{n}^{\circ}$ 183 (pp. I06-III). Sobre esta etapa de la vida de Conón, cf. Barbieri 1955: 55-73, mientras que para el acceso al trono y los primeros años de reinado de Evágoras, anteriores a su revuelta del Gran Rey, véase Costa 1974.

2 D.S. I4.39.I. Otras fuentes difieren en los detalles que rodean el nombramiento de Conón como almirante persa. Así, en el Evágoras de Isócrates (55) el rey chipriota ejerce una destacada mediación ante «los generales del rey persa» (presumiblemente Farnabazo), mediación que sin embargo es suprimida en el relato de los mismo hechos en su Filipo (63). Según Nepote (Con. 2-3) y Justino (6.I), con leves variantes, Conón releva en el cargo a Tisafernes, acusado de revuelta -con base o sin ella- por Farnabazo. Ni este último ni Evágoras tienen protagonismo en el relato de Ctesias ( FGrH $688 \mathrm{~F}$ 30), seguido, también con 
protagonismo en la escena internacional y enseguida, merced a sus éxitos en Rodas y sobre todo en $\mathrm{Cnido}^{3}$, lo haría también en una Atenas que le reservaría una gloria sin precedentes. Sin embargo, con toda su influencia sobre la política ateniense de finales de la década de 390, Conón no dejó en ningún momento de servir al Gran Rey. Es la pretensión de este trabajo analizar su peculiar trayectoria en estos críticos años de la guerra de Corinto.

Desde su creación, las actividades de la flota fenochipriota ${ }^{4}$ de Farnabazo y Conón se fueron incrementando hasta llegar a constituir una seria amenaza para la hegemonía naval lacedemonia en el Egeo, sobre todo a partir de la conquista y control de la estratégica base naval de Rodas, donde Conón además propició en el verano de 395 la instauración de un régimen democráticos; desde la isla no sólo se podían apoyar las operaciones terrestres en suelo cario, sino que también cumplía un importante papel de control del acceso al Egeo meridional y como escala en la ruta del grano egipcio que tenía como destino el Ática ${ }^{6}$.

Como respuesta el rey Agesilao II, inmerso en su cruzada «panhelénica» en Asia Menor, encomendó a las ciudades griegas de la región preparar ciento veinte naves

ciertos matices, por Plutarco (Art.21.2-4), en el que es el propio médico griego, entonces en la corte persa, quien, junto a otros consejeros, intercede ante el Gran Rey en favor de Conón. Costa 1974: 48 intenta entretejerlas todas suponiendo varias fases en la negociación. Pese a que Conón era por entonces un apátrida, Corsaro 1994: 117 ve en este nombramiento una apertura diplomática persa hacia Atenas, un medio de incitarla al abandono de la alianza espartana. Sobre los preparativos y movimientos persas en estos años se consultará con beneficio Falkner 1992: 239-242.

3 De los avatares de la flota fenochipriota de Farnabazo y Conón en el contexto de los orígenes de la guerra de Corinto nos hemos ocupado recientemente en Fornis 2007a, pero para los detalles más específicos véase March 1997.

4 X. HG. 4.3.II; D.S. 14.83.6. Perlman 1968: 26I piensa que pudo haber algunos barcos atenienses que hubieran seguido el ejemplo de Deméneto (Hel. Oxy. 6), pero es difícil porque Atenas no tenía más que una docena de naves y precisamente el caso de Deméneto fue excepcional, como demuestra la repercusión

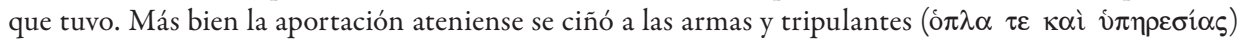
canalizados a través de la facción de Epícrates y Céfalo, como relata Hel. Oxy. 7.I, y seguramente no en gran cantidad, dado que se hacía en secreto para no violar el acuerdo de capitulación (son probablemente los exiliados y voluntarios a los que re refiere Pl. $M x .245$ a, aunque aquí la ciudad conoce y permite su envío; cf. también Isocr. 4.I 42, según el cual los persas se sirvieron de los remeros atenienses).

5 D.S. 14.79.6-8; Androt. FGrH 324 F 15 apud Paus. 6.7.6.

6 Ps.Dem. 56: passim. Las consecuencias negativas que la pérdida de la base naval rodia tuvo, a efectos logísticos, sobre la campaña asiática de Agesilao son expuestas por Falkner 1992: 243. 
con las que reforzar, en la primavera de 394, su propia armada para encarar con garantías a la del bárbaro ${ }^{7}$. El Euripóntida, que había recibido el mando naval de las autoridades patrias tras la victoria sobre Tisafernes en el río Pactolo ${ }^{8}$, lo delegó en su cuñado Pisandro, en lo que constituye un nombramiento de carácter extraordinario y ejemplo claro de nepotismo ${ }^{9}$. Y es que el propio Jenofonte, que no puede ser sospechoso de antilaconismo, describe a Pisandro como hombre ambicioso y enérgico, mas inexperto en cuestiones de organización y estrategia naval º, a lo que Plutarco añade que había hombres mejor preparados para el puesto ${ }^{\text {II }}$, por lo que sólo cabe suponer que primaron en el Euripóntida consideraciones políticas de orden interno, quizá como medio de fortalecer su posición en las relaciones de poder en el seno de Esparta en una coyuntura especialmente delicada ${ }^{12}$. La batalla de Cnido pondría en evidencia la escasa fortuna de la decisión real.

Apenas contamos con información que nos permita reconstruir la decisiva batalla naval librada cerca de Cnido, a principios de agosto del año 394 -el eclipse solar del día 14 marca la recepción de la noticia en la frontera norte de Beocia por parte de Agesilao ${ }^{\mathrm{I}}$-, sobre todo en contraste con la que tenemos acerca de sus consecuencias.

7 X. $H G$. 3.4.28. Es probable que no se alcanzara tal número, pues Pisandro sólo dispondrá de 85 en la batalla de Cnido.

8 Hecho insólito, pues por primera vez en la historia de Esparta un solo individuo aglutinaba la dirección conjunta de los ejércitos terrestre y naval.

9 El navarco oficial de ese año era Quirícrates (cf. Pareti 1908-09: 135-137, aceptado por Barbieri 1955: I 40-I 4I, que aporta otros ejemplos de cargos extraordinarios, el más conocido de los cuales es sin duda el servicio de Lisandro como epistoleús en la batalla de Egospótamos, dada la imposibilidad de desempeñar la navarquía una segunda vez: X. HG. 2.I.6-7; Plu. Lys. 7.2-3). Durante la guerra de Corinto tenemos el caso de Teleutias, hermanastro de Agesilao, que fue navarco en $389 / 8$ (X. HG. 5.I.13) y un año antes había dirigido la campaña de Rodas (X. $H G$. 4.8.23-24).

Io X. $H G .3 .4 .29$.

II Plu. Ages. Io.II.

I2 Basándose en el testimonio de Plutarco (Ages. 20.3-4), Hamilton 1979a: 219-220 sugiere que el peligro podía venir de la facción de Lisandro, a quien se atribuye maquinaciones encaminadas a dar un golpe de Estado. Con todo y con eso, el rey euripóntida se caracterizó por hacer amplio uso de prácticas de nepotismo, como Cartledge 1987: 26 ha subrayado bien.

I3 X. HG. 4.3.10; Plu. Ages. 17.4-5. Es sabido que, en un ardid de jefe militar, Agesilao ocultó a sus hombres la derrota en la naumaquia y la muerte en ella de Pisandro, presentándola como una victoria de las armas espartanas con el fin de no minar su moral y evitar posibles deserciones, en especial entre los griegos de Asia. 
Ante la falta de atención de Jenofonte por los asuntos del mar ${ }^{14}$, la fuente más explícita es Diodoro ${ }^{15}$, que naturalmente deriva de las casi perdidas Helénicas de Oxirrinco, pero que, además de caer en uno de sus frecuentes despistes cronológicos ${ }^{16}$, sitúa la naumaquia en un lugar erróneo -cerca de Fisco, a unos I20 kilómetros de Cnido, siempre que no se acepte la existencia de otro lugar con idéntico nombre en el Quersoneso ${ }^{17}$ - y recoge una cifra de «más de noventa» trirremes de Conón por ochenta y cinco de Pisandro, cuando él mismo, en un pasaje anterior ${ }^{18}$, sitúa a Conón entrando en Rodas con algo más de ochenta naves, para recibir después otras ochenta fenicias y diez cilicias, lo que haría un total de ciento setenta ${ }^{19}$. Por su parte, Jenofonte alude a la batalla de manera indirecta -bien que suficiente para refrendar su localización $\pi \varepsilon p \grave{~ K v i ́ \delta o v, ~ « e n ~}$ torno a Cnido»- y se limita a afirmar, sin dar números, que la flota lacedemonia estaba en franca inferioridad frente a la combinación de la fenicia de Farnabazo y la helena -fundamentalmente chipriota ${ }^{20}$-, de Conón; según el historiador ateniense todo el ala izquierda de la armada lacedemonia, integrada por aliados, huyó ya antes del choque y el resto lo hizo durante el mismo, con excepción de Pisandro, que prefirió una muerte honrosa en combate antes que una ignominiosa retirada ${ }^{21}$. La débâcle espartana no

I4 Véase al respecto Fornis 2004b: esp. 179. Jenofonte no aborda la batalla de Cnido al comienzo de la sección narrativa de acontecimientos navales, como cabría esperar, sino que inserta la noticia de la derrota en vísperas del enfrentamiento de Coronea, justo después de la victoria de Agesilao sobre la diestra caballería tesalia, según Tuplin 1993: 68 para establecer un marcado contraste entre el mérito de Agesilao y el demérito de su cuñado Pisandro.

I5 $14.83 .4-7$.

i6 Fecha la batalla en el arcontado de Diofanto (395/4), cuando ya había entrado en oficio Eubúlides $(394 / 3)$.

17 Como hizo por ejemplo Judeich 1892: 75, aceptado por Barbieri 1955: 145-146, que aporta alguna referencia en este sentido.

I8 14 .79.6-8.

19 La mayoría de los estudiosos modernos tiende a pensar que el Sículo duplicó la cifra, aunque algunos como Beloch 1922: 76 y Pascual González 1995: 782 piensan que el número de noventa se refiere sólo a las naves chipriotas mandadas por Conón y que hay una laguna en i 4.83.4 en la que faltan las otras ochenta naves, las mandadas por Farnabazo; Barbieri 1955: 120-I23 prefiere suponer que el rey sidonio Actón pudo retirarse con sus ochenta naves, bien por divergencias en el mando con Farnabazo, bien por temor de un ataque de los rebeldes egipcios.

20 Isoc. 9.56, 67-68.

$2 \mathrm{IX}$ X. $H G$. 4.3.II-I2. Otras fuentes literarias complementarias y por lo general indirectas sobre la batalla y sus consecuencias son: Philoch. FGrH 328 F I45; Eph. FGrH 70 T 20; Lys. 2.60; 19.28; 
admite paliativos y supuso el desvanecimiento de los frutos traídos por la victoria sobre la arché ateniense en 404, de manera que no es extraño que las fuentes griegas la percibieran como el fin de la hegemonía naval de Esparta ${ }^{22}$-Teopompo eligió además este punto para cerrar sus Helleniká23 ática, pecan de helenocentrismo al acentuar la prominencia de Conón y minimizar la persa en estos acontecimientos.

En efecto, los cincuenta trirremes y quinientos hombres capturados a los lacedemonios en Cnido, es decir, más de la mitad de la flota, no fueron sino un mal menor comparado con la inmediata expulsión de guarniciones y harmostas lacedemonios a lo largo de toda la costa minorasiática y las islas del Egeo oriental. Mientras estos espartanos encontraban refugio en Abido y $\mathrm{Sesto}^{24}$, a ambos lados del estrecho, que seguían en poder del espartiata Dercílidas, las ciudades fueron recobrando la libertad ( $\tau \grave{\eta} v$

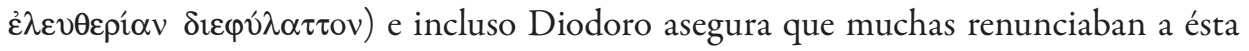
para agruparse $\pi \varepsilon \rho \grave{~ K o ́ v \omega v \alpha, ~ l o ~ q u e ~ q u i e r e ~ d e c i r ~ q u e ~ a c o g i ́ a n ~ d e ~ b u e n ~ g r a d o ~ l a ~ t u t e l a ~}$ persa $^{25}$. Cnido cristaliza, pues, lo que Eugene Costa ha denominado «a consistent and

Isocr. 4.I20, I 42; 5.63-64; 9.56 y 68; I2.56; Nep. Con. 4.4; Plu. Art. 21.I, Ages. 17.2-3 y Mor. 345 E; Paus. 6.3.16; Din. 1.75; Aristeid. 1.280; Polyaen. I.48.5; Iust. 6.3.12-4.1; Oros. 3.1.12-15.

22 En particular Isoc. 12.56 y D.S. I 4.84 .4$.

23 D.S. 14.84 .7 .

24 A propósito de la emboscada que Ifícrates tendió a Anaxibio en Cremaste, en 389, X. HG. 4.8.39

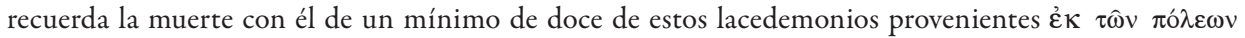

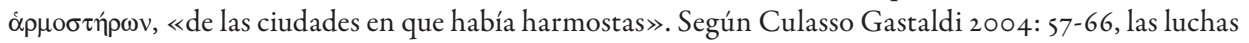
internas entre partidarios de Atenas y de Esparta que tendrían lugar en Abido al calor de estos acontecimientos podrían procurar el escenario de la intervención (infructuosa) de dos familias abidenas, cuya fidelidad y valor fueron recompensados con la proxenía y la evergesía por el dêmos ateniense ( $\left.I G \mathrm{II}^{2} 49\right)$. Como en tantos otro casos, lo fragmentario de la inscripción, el amplio margen de datación que proporcionan los criterios estilísticos y la escasa información que poseemos de la historia interna de esta ciudad y de esta región hacen que no falten otros contextos (se ha fechado por otros eruditos desde 4io hasta la década de 370 , en «ambientazione possibile», como la italiana reconoce; de hecho ella misma propone una segunda opción, con la expedición de Trasibulo al Helesponto como telón de fondo).

25 X. HG. 4.3.II-I2 y 8.I-7; D.S. I 4.83.5-7 y 84.3-4 especifica los nombres de Cos, Nisiro, Teos, Quíos, Mitilene, Éfeso y Eritras (el Sículo sigue un orden geográfico que sólo rompe la isla de Teos, por lo que Robert 1934: 43-44, propuso juiciosamente enmendarla por Telos y prácticamente todos los estudiosos lo han seguido) entre las nuevas aliadas de Conón y Farnabazo, que presumiblemente aportarían en adelante contingentes a la armada persa (Seager 1967: 102 no desecha la idea de que Diodoro se esté refiriendo a la peculiar alianza que emitió las monedas $\Sigma \Upsilon \mathrm{N}$, sobre las cuales se encontrará un status quaestionis en 
successful policy to destroy Spartan sea-power and to regain Persian control of Asia Minor ${ }^{26}$.

La concesión de autonomía y el compromiso de no establecer guarniciones por parte de Farnabazo -a instancia de Conón- proclama que los persas están asumiendo el papel de árbitros de los asuntos de las ciudades griegas orientales ${ }^{27}$. Así parece confirmarlo una inscripción milesia que puede fecharse con seguridad a finales de 392 o comienzos de 391 en la que el káranos y sátrapa de Lidia Estruses -el Estrutas de Jenofonte- actúa como mediador, en representación de Artajerjes II, en una disputa entre Mileto y Miunte a causa de unas tierras situadas en el valle del Meandro ${ }^{28}$. Estruses delega a su vez en una comisión de jueces llegados de doce ciudades de Jonia, en calidad de asesores, cuya decisión no es vinculante y depende en última instancia del káranos, que da la razón finalmente a los milesios. La inscripción demuestra que las ciudades jonias disfrutaban de independencia, pero al mismo tiempo que reconocían a Persia como el poder hegemónico y regulador en la región antes de que la paz del Rey legitimara la soberanía persa sobre estos territorios y, con ella, el dominio absoluto sobre las ciudades griegas costeras.

Mientras Farnabazo regresaba a su casa, Conón invernó en el Helesponto, donde intentó atraer a las ciudades de la región para su causa. Con la llegada de la primavera, reunidos de nuevo el sátrapa y su almirante, dotaron más naves y contrataron mercenarios con los que reanudaron su periplo hacia el Egeo central, donde no tardaron en hacerse con el control de las Cícladas. Si de una parte sabemos por el Eginético de

Fornis 2004b: 186). Sabemos sin embargo que no todos los harmostas fueron expulsados o evacuados, ya que unos cinco años después Trasibulo se encuentra uno al frente de una guarnición lacedemonia en Metimna (Lesbos), donde no cabría esperarlo (X. HG. 4.8.28; D.S. I 4.94.3). Las fuentes hablan de restauración del principio de autonomía en las ciudades, pero no dicen que éstas se dotaran de regímenes democráticos ni que se vincularan con Atenas, como sobreentienden Cloché 1919: 169, Accame 1951: 97, Barbieri 1955: 155-156 (《in forma più o meno larvata») y más recientemente Badian 1995: 84.

26 Costa 1974: 49.

27 Ruzicka 1997: 113.

$28 S I G \mathrm{I}_{34}=S G H I \mathrm{n}^{\circ}{ }_{113}=G H I \mathrm{n}^{\circ}{ }_{16} 6=$ Piccirilli $1973: \mathrm{n}^{\circ} 36$. Estrutas alcanza Sardes en algún momento del invierno de 392/I (cf. Funke 1980: 94 con n. 8I; Fornis 2005: 278-279) y en la primavera siguiente, la de 39I, los lacedemonios inician una contraofensiva naval en el Egeo que les permite recuperar ciudades como Éfeso, Samos o Priene, que aquí forman parte de la dodecápolis jonia que asesora en el arbitraje persa. 
Isócrates que Trasíloco, un aristócrata sifnio, fue expulsado de su patria junto con otros miembros de su clase social cuando Pasino - posiblemente un mercenario a las órdenes de Conón- tomó Paros con ayuda de antiguos desterrados, para acabar encontrando refugio en Egina ${ }^{29}$, por otra la epigrafía nos confirma que la anfictionía de Delos, con sede en el importante santuario pítico en esta isla, vuelve a situarse bajo protección ateniense y se reanuda la celebración de la pentetéride suprimida tras Egospótamos ${ }^{30}$. Mayor peligro para Esparta revestía que Melos se convirtiera en base naval para desencadenar incursiones de castigo contra las costas lacedemonias y mesenias, hecho que no se producía desde el año 409/8. Jenofonte no lo explicita, pero sin duda en la mente de Conón anidaba la idea de fomentar la revuelta de hilotas como medio de poner en jaque los cimientos económicos e ideológicos del estado lacedemonio ${ }^{31}$. El primer ataque se dirigió contra Feras, en el golfo de Mesenia, donde arrasaron los campos, para continuar con eventuales desembarcos en distintos lugares de la costa que trataban de causar el mayor daño posible, hasta que la escasez de puertos naturales, la amenaza de llegada de refuerzos ${ }^{32}$ y la falta de víveres les hicieron desistir y poner proa a Citera ${ }^{33}$.

La isla lacedemonia de Citera, a unos diez kilómetros del sudeste del Peloponeso y habitada por población perieca, reviste una gran importancia estratégica, tanto como escala en las comunicaciones navales con el sur y sudeste del Mediterráneo como por ser punto de llegada del vital grano libio y egipcio. De creer a Pausanias ${ }^{34}$, Citera habría sido tomada durante su periplo peloponésico de 455 por el estratego ateniense Tólmides, quien se sirvió de ella como cabeza de puente para desembarcar ataques sobre las costas lacedemonias. En 424, durante la guerra arquidámica, un año después del desastre de Esfacteria, la amenaza fue mucho mayor. Tucídides precisa que Citera estaba al cuidado

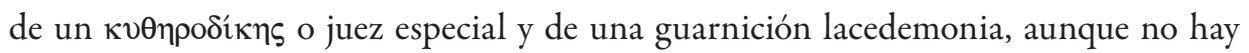

29 Isoc. 19.18-20, 38-40, crudo testimonio sobre la situación de stásis que se vivía en Sifno como consecuencia de la pugna entre las potencias hegemónicas por hacerse con la isla.

$30 I G \mathrm{II}^{2} \mathrm{I} 633, \mathrm{I} 634$ y 1635 .

31 Cartledge 1979: 283 piensa que la idea pudo partir de Conón, aconsejado a su vez por los mesenios que, según el anónimo de Oxirrinco (20.3), le rodeaban.

32 La experiencia de la guerra del Peloponeso había llevado a los espartanos, según Cartledge, ibid., a disponer de destacamentos móviles que podía alcanzar mucho antes el lugar del ataque.

33 X. $H G$. 4.8.7.

34 I.27.5.

$\mathrm{DH}_{34 / 2}-2008$ 
trazas de ellos en el subsiguiente relato de la captura de la isla por parte de Nicias ${ }^{35}$. Tampoco ahora el sátrapa y su avezado lugarteniente ateniense parecen haber encontrado especial resistencia entre los citerios -Jenofonte no menciona ni al magistrado ni a la guarnición, que presumiblemente seguían siendo enviados anualmente desde Esparta $^{36}$-, pues tomaron la ciudadela de la capital al primer asalto y enseguida los defensores alcanzaron un acuerdo de capitulación por el que abandonaban la plaza a cambio de que no se les inquietara en su retirada hacia Lacedemonia ${ }^{37}$. Con la reparación del circuito defensivo y la guarnición de mercenarios al mando del harmosta [sic] ateniense Nicofemo ${ }^{38}$, la isla estaba preparada para servir mucho mejor que Melos a la práctica de

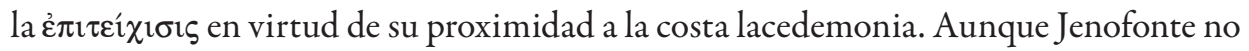
es Tucídides, debemos suponer que la inquietud y el nerviosismo cundieron en Esparta como tres décadas atrás, si no en mayor medida, pues cabe recordar que la peligrosa conjura de Cinadón estaba aún muy reciente ${ }^{39}$. Se ha sugerido incluso, con cierto fundamento, que la captura de Citera se encuentra en la raíz de la iniciativa diplomática de acercamiento a Persia abanderada por Antálcidas en la primavera siguiente (vid. infra $)^{40}$. Con Citera asegurada y acondicionada, Farnabazo y Conón partieron hacia

35 Th. 4.53-54; cf. Fornis 1999: 54-55 para el epiteichismós practicado por Nicias en Citera. Carledge 1979: 244-245 supone que Esparta habría retirado la guarnición de hoplitas para evitar que se repitiera lo sucedido en Esfacteria, esto es, que quedaran aislados y luego fueran fácilmente apresados. Es dudoso si Heródoto vivió lo suficiente para conocer estos desarrollos, pero lo cierto es que en 7.235, referido al año 480 , pone en boca del exiliado rey espartano Demarato el consejo a Jerjes de ocupar Citera como medio de llevar la guerra al territorio de Esparta y evitar así que ésta ayude a los demás griegos.

36 Cartledge, ibid., recuerda que una inscripción del siglo IV ( $I G \mathrm{~V}$ r.937) constata la presencia de un harmosta espartano en la isla. En opinión del historiador británico (p. 283), en esta ocasión la guarnición habría regresado por los mismos motivos que treinta años antes.

37 Se han preservado restos de murallas que datan de finales del siglo $\mathrm{V}$ o principios del IV y que Foss 1974-75 cree serían levantadas por Conón, pero como bien indica Falkner 1992: 249 con n. 62, igual podrían ser también parte de las defensas espartanas. Sobre el acuerdo de capitulación, Fernández Nieto 1975: $\mathrm{n}^{\circ} 130$.

38 Jenofonte emplea aquí el término técnico espartano aplicado a un oficial de la flota persa con funciones similares y no a un estratego ateniense (correctamente Develin 1989: 207 ni siquiera lo recoge como dudoso; cf. también Seager 1967: 102 y Funke 1980: 82 n. 33).

39 Sobre la conspiración de Cinadón, véase ahora Fornis $2007 \mathrm{~b}$, que recoge y discute la literatura precedente.

40 Lewis 1977: 145, aceptado por DeVoto 1986: 194. Cartledge 1979: 284 aporta argumentos arqueológicos de cierta consistencia como para defender que la flota persa llevó a cabo una incursión sobre la 
el istmo de Corinto, donde en una sesión del sinedrio el primero animó a los coligados

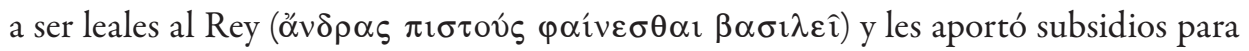
proseguir con ardor la guerra contra Esparta ${ }^{41}$.

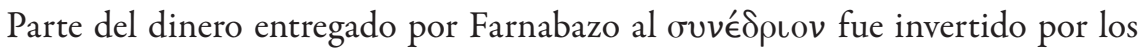
corintios en equipar una flota que, bajo el mando de Agatino, se enfrentó con éxito a

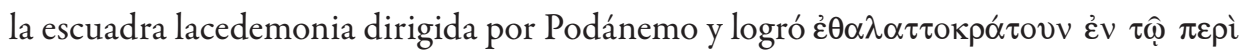

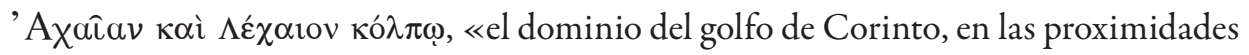
de Acaya y Lequeo» ${ }^{42}$. Hasta ese momento los corintios se habían mostrado incapaces de defender por sí mismos y con sus propios recursos este área estratégica tan vital para ellos, lo que da idea de la crisis económica abierta por la guerra del Peloponeso en un estado tradicionalmente próspero ${ }^{43}$. La fecha de estas operaciones navales es incierta, pero puesto que la preparación y equipamiento de la flota presupone que Lequeo se hallaba aún en manos de los corintios y sus aliados, debieron de tener lugar en la primavera o comienzos del verano de $392^{44}$, justo antes de que en agosto, gracias a la traición de los oligarcas corintios Pasimelo y Alcímenes, el polemarco lacedemonio Praxitas se apoderase de los Muros Largos y presumiblemente del mismo puerto ${ }^{45}$. La «talasocracia» corintia de la que habla Jenofonte se probó, pues, efímera. Para cuando Proeno

isla de Anticitera, un islote que se encuentra a mitad de camino entre Citera y Creta, episodio que sería obviado tanto por Jenofonte como por Diodoro.

4I X. HG. 4.8.8. En lugar del servilismo hacia el persa denotado por Jenofonte, D.S. I 4.84.4-5 presenta a Farnabazo entablando una alianza formal con el Consejo de Corinto; sin embargo, Accame 1951: 97 está sin duda en lo cierto al creer que el Sículo no hace sino traducir en términos jurídicos lo que no fue más que una ayuda material, argumentación que ha gozado de fortuna entre los estudiosos modernos: Barbieri 1955: 160; Seager 1967: 107; Funke 1980: 71 n. 2; contra Judeich 1892: 81; Strauss 1986: 126. A diferencia de Alonso Troncoso 1997: 55-56, no creemos necesariamente que el sinedrio ístmico contara con una caja común de guerra, sino que cada estado empleó el dinero recibido a su conveniencia, como vamos a ver.

$42 \mathrm{X} . H G$. 4.8.Io. Nos encontramos una vez más ante los problemas financieros que agobiaban a los estados griegos que habían sufrido con severidad la dura guerra del Peloponeso. Según Salmon 1984: 354, la breve y excepcional emisión de pequeñas monedas de oro corintias de principios del siglo IV fue probablemente acuñada con el oro del Gran Rey para subvencionar las operaciones de Agatino en el golfo de Corinto. Otro tanto piensa Cloché 1952: 107-108 del estado federal beocio, que acuña oro por vez primera junto a piezas en electrón y plata.

43 Fornis 2007a: 201-202.

44 Accame 1951: ro5; Funke 1980: 84 con n. 40.

45 X. HG. 4.4.7-13; cf. D.S. 14.86.2-4; Andoc. 3.18. 
sustituyó a Agatino como almirante, los corintios habían sido despojados ya del estratégico Lequeo, lo cual les forzó a abandonar a su vez el puerto aqueo de Río, que utilizaron hasta entonces como base naval y que ahora pasaba de nuevo a manos del espartano Herípidas ${ }^{46}$. En la estación bélica del año siguiente, una vez constatado el fracaso de las negociaciones de paz (vid. infra) y con el apoyo de una nueva flota construida a buen seguro con el dinero entregado en secreto por Tiribazo ${ }^{47}$, Teleutias volvió a controlar el golfo ${ }^{4}$, vital para los espartanos en la medida en que de él dependía la comunicación con sus aliados de Grecia central, pues la presencia de las fuerzas del sinedrio en la ciudad de Corinto y en el istmo impedía la salida por vía terrestre del Peloponeso. Desgraciadamente esto es todo lo que sabemos por el breve y deficiente relato de Jenofonte, como de costumbre escasamente interesado por las operaciones navales.

Pero sin duda el estado mejor capitalizó la inyección económica persa fue Atenas, dado que el grueso de los fondos fue empleado en primer lugar para el reclutamiento en el Helesponto de una fuerza de peltastas mercenarios altamente especializada y efectiva que serían destinada a la Corintia bajo las órdenes de Ifícrates de Ramnunte ${ }^{49} \mathrm{y}$, en segundo lugar, en un acción cargada de simbolismo, para impulsar definitivamente el proyecto de reconstrucción de las fortificaciones del Pireo y de los Muros Largos que lo unían a la ciudad de Atenas, demolidos unos y otros en abril de 404 bajo la supervisión del espartano Lisandro ${ }^{\circ}$. El responsable de ambas medidas fue Conón, que a comienzos del verano de 393 hace su entrada triunfal en el Pireo a la cabeza de ochenta trirremes, en medio de una población ateniense que transpira euforia y que saluda al otrora apátrida como al genuino salvador de la ciudad ${ }^{51}$. Los historiadores modernos

46 X. HG. 4.8.II. Cf. Accame 1951: 108; Salmon 1984: 363; Buckler 2004: I1 4-II5.

47 X. $H G$. 4.8.16. Cf. DeVoto 1986: 194-195.

48 X. $H G$. 4.8.II.

49 A comienzos de la estación bélica de 390 este contingente de $\pi \epsilon \lambda \tau \alpha \sigma \tau \alpha i ́$ aniquiló casi por completo una $\mu$ óp $\alpha$ o batallón del ejército lacedemonia, lo que garantizó a su comandante Ifícrates una fama perenne y el paso a los anales de la historia militar como uno los estrategos griegos más resolutivos, audaces e innovadores. Sobre éste y otros logros de Ifícrates en la Corintia, véase Fornis 2004a.

so X. $H G \cdot 2.2 .23$.

5I X. HG. 4.8.9-IO; D.S. i 4.85.2-3, que en uno de sus habituales errores cronológicos sitúa el acontecimiento el año anterior, al comienzo del arcontado de Eubúlides (394/3). Más difícil de precisar es 
acostumbran a hablar de «síntomas»-como si de una enfermedad o un mal se tratasede una voluntad imperialista, de un deseo de reverdecer el imperio extinto con la guerra del Peloponeso.

Sin embargo, la Asamblea ateniense ya había aprobado la restauración de las defensas de la ciudad y del puerto al menos un año antes de la llegada de Conón, presumiblemente en el verano de 395 -apenas sellada la alianza con los beocios o bien justo después de la batalla de Haliarto-, bajo la influencia de la personalidad política del momento, Trasibulo de Estiria ${ }^{52}$. Así lo proclaman, frente al silencio de Jenofonte ${ }^{53}$, dos fragmentos de inscripciones que contemplan distintos pagos destinados a sufragar dichas obras. El primero de ellos está fechado en el arcontado de Diofanto (por tanto año 395/4), en el mes de Scirophorión (duodécimo del calendario ático), que viene a coincidir con nuestro junio (aunque eventualmente puede prolongarse hasta julio e incluso principios de agosto) ${ }^{54}$. El segundo epígrafe data ya del siguiente arcontado,

el momento concreto del regreso, quizá la penúltima pritanía, como propone Funke 1983: 154-156, que si bien hace notar la dificultad de saber si aún correspondía al final del arcontado de Eubúlides o al inicio ya del de Demóstrato (393/2) -pues las fluctuaciones del calendario ático no permiten una equivalencia exacta con el juliano-, se decanta por la primera opción en virtud del testimonio de $I G \mathrm{II}^{2} \mathrm{I}_{42} 4$ a (1l. 346-349), un listado de ofrendas del tesoro de Atenea entre las que se encuentra una corona dedicada por Conón durante el arcontado de Eubúlides (sin duda la misma mencionada por Dem. $22.72=24 \cdot 180$, que conmemoraba la victoria sobre los lacedemonios en Cnido).

52 Sealey 1956: 183; Perlman 1968: 261; Alfieri Tonini 1972: 131-132; Buck 1998: 99. Funke 1980: 113 prefiere dejar abierta la cuestión de si fue iniciativa de Trasibulo, aunque se puede inferir de X. $H G$. 3.5.16.

53 En su relato ( $H G$. 4.8.9-10) Conón, erigido en gran protagonista, propone a Farnabazo que le permita utilizar a los remeros de la flota para la reconstrucción de las murallas, como si ésta aún no hubiera comenzado.

$54 I G \mathrm{II}^{2}{ }_{1656}=S I G \mathrm{I}_{24}=S G H I \mathrm{n}^{\circ}{ }_{107} \mathrm{~A}=G H I \mathrm{n}^{\circ}$ 9. Esto significa que, de acuerdo con nuestra datación de la batalla de Nemea en la segunda quincena de julio de 394 (Fornis 2003: I 43-I 44 con n. II), los trabajos de reconstrucción de las fortificaciones seguramente habían comenzado con anterioridad (pace Hamilton 1979a: 223-224, para quien «resulta muy tentador pensar que hay una conexión causal entre estos dos hechos», sobre todo cuando tras dicho choque quedó de manifiesto que la lealtad de Corinto flaqueaba -en razón de la disensión interna que padecía- y un hipotético cambio de bando franquearía a Esparta las puertas del Ática; recordemos que el norteamericano fecha el enfrentamiento de Nemea antes de la salida del arcontado de Diofanto el is de julio). Como ha objetado Cook I98I: 327 con n. 2I, Hamilton parte de la base de que con esta entrega de dinero se iniciaron las obras, cuando en realidad sólo sabemos que fue un desembolso -bastante exiguo, por lo demás-, que no tiene que ser necesariamente el primero. En cualquier caso, por encima de la cantidad, lo realmente significativo es el hecho en sí, demos- 
el de Eubúlides (394/3), y presenta el interés añadido de confirmar la colaboración de aliados en estos trabajos -Jenofonte menciona la ayuda voluntaria de beocios y de gentes de otras ciudades, pero asociada de nuevo a la llegada de Conón-, concretamente la de un beocio llamado Demóstenes que percibe 790 dracmas por el transporte de bloques de piedrass.

Esto no obsta para negar a Conón el mérito de ser en el gran catalizador de una empresa imposible de imaginar en tan corto plazo de tiempo sin los subsidios persas, cincuenta talentos según Nepote -complementados por aportaciones salidas del pecunio personal del mismo Conón-, y sin la ardorosa entrega no sólo de los atenienses, sino también de quinientos beocios y de gentes venidas de otras ciudades aliadas ${ }^{56}$. Como máximo abogado de la idea de recuperar el imperio ateniense del siglo anterior, Conón era consciente de que las murallas no sólo garantizaban la independencia de la ciudad, sino que, al hacer de Atenas esa «isla temistoclea» siempre abastecida desde el mar, ponían los cimientos de cualquier futuro intento de expansión y dominación marítima en el Egeo. Adquiere así pleno sentido uno de los escasos testimonios conservados de Cratipo, el historiador ateniense del siglo IV que muchos estudiosos identifican con

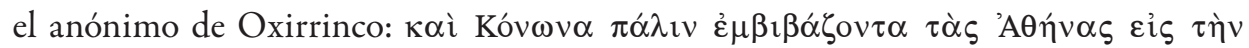
$\theta \alpha ́ \lambda \alpha \tau \tau \alpha \nu$, «Conón dirigió a Atenas nuevamente hacia el dominio del mar» ${ }^{57}$, o los fragmentos preservados de comedias representadas en 393, que equiparaban a Conón con Odiseo y a sus constructores con cíclopes ${ }^{58}$. Precisamente esta «ciclópea» tarea de reconstrucción de las defensas dio trabajo y salario durante casi dos años a los estratos

trativo de que el pueblo ateniense parecía determinado, incluso antes de la llegada de Conón, a rescatar viejas políticas imperiales (cf. Seager 1967: 103: «Conón no hizo más que animar y explotar una manifestación de imperialismo popular que en forma alguna dependía de su política personal»; contra Pritchett 1974: I20 n. 2I, para quien la importancia de este testimonio epigráfico se ha sobredimensionado).

$55 I G \mathrm{II}^{2}{ }_{1} 657=S I G \mathrm{I}_{25}=S G H I \mathrm{n}^{\circ}{ }_{107} \mathrm{~B}=G H I \mathrm{n}^{\circ} 9$.

56 X. HG. 4.8.9-II; D.S. I 4.85-86; Isoc. 5.64; Nep. Con. 4.5; Iust. 6.5. Las obras parecen haber concluido para cuando Lisias compuso su Discurso fúnebre, en 392 ó 391, a juzgar por el parágrafo 63, en el que, por cierto, en consonancia con el tono crítico hacia Conón del discurso, el mérito de «levantar nuevos muros en lugar de los derribados» viene adjudicado a los demócratas de File (entre los que se cuenta Trasibulo de Estiria). La misma fecha de 392/I se desprende también de $I G \mathrm{II}^{2}$ I657-1664.

57 FGrH 64 T 2 apud Plu. Mor. 345 D-E. Sobre la tendencia filológica e historiográfica que identifica a Cratipo con P, véase Fornis 2004 b: I8I n. I7.

58 Strauss 1986: 127 n. 24 cita los fragmentos recogidos en la obra clásica de Edmons. 
más humildes de la ciudad, beneficiarios como antaño de los proyectos imperiales ${ }^{59}$. En su memoria estos muros serán llamados en adelante «cononianos» ${ }^{60}$.

Al igual que aconteciera con Lisandro tras la guerra del Peloponeso, por doquier se celebra a Conón como liberador de Grecia, se le erigen estatuas y se le conceden privilegios ${ }^{6}$. No puede sorprender que las fuentes griegas, y muy especialmente la oratoria ática, hagan suyos los logros de Conón al tiempo que ignoran o restan importancia al hecho de que éste no es sino un instrumento del poder persa ${ }^{62}$. En su patria, Atenas, de la que se había desterrado con amargura doce años antes, se le tributan honores extraordinarios que le elevan a la categoría de héroe local y que no tienen otro precedente que el de los tiranicidas Harmodio y Aristogitón, pues también él, nos dice Demóstenes, «había puesto fin a una tiranía nada leve» ${ }^{63}$. Estos honores consistieron en la conce-

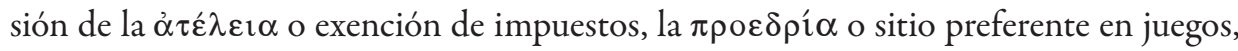
fiestas y representaciones de carácter público, una corona de olivo y la erección de dos estatuas, una en el ágora -la primera de un ciudadano aún vivo, muy significativamente frente al pórtico de Zeus Eleuterio (Liberador)-, y la otra en la Acrópolis ${ }^{64}$. Como ha apuntado Hamilton, ni siquiera Temístocles tras el rechazo del bárbaro, ni Pericles en la cima de su poder, ni Trasibulo con la caída de los Treinta y la restauración de la democracia merecieron semejantes elogios y distinciones ${ }^{65}$. Claramente este hecho

59 Sobre el curso y características del circuito cononiano, véase Garland 1987: 165-166.

60 Buck 1998: 106 aprecia en ello «un intento deliberado de ignorar el hecho de que Trasibulo comenzó la refortificación de Atenas».

6I Paus. 6.3.16 (Samos, Éfeso); $S I G$ I26 = SGHI n ${ }^{\circ}$ 106 = GHI no 8 (Eritras); cf. así mismo Dem. 20.7 I.

62 De igual forma, como recuerda Debord 1999: 252 n. 153, ninguna estatua, decreto o cualquier otro tipo de testimonio en honor de Farnabazo - salvo las monedas de Mitilene- «ha sobrevivido a las peripecias de la historia ulterior».

63 Dem. 20.70.

64 Dem. 20.69-70; Isoc. 5.64; 7.12 y 65; 9.56 y 68; Din. I.I4; Paus. I.3.2 y 24.3, 6.3.16; Nep. Tim. 2.3; $I G \mathrm{II}^{2} 26$. Nótese que en Jenofonte no encontramos huella de tales distinciones, sino que es en cambio Farnabazo el objeto de «las alabanzas y los dones de hospitalidad de las islas y las ciudades costeras» (HG. 4.8.2).

65 Hamilton 1979b: 89, aunque no compartimos la tesis de fondo del autor norteamericano en cuanto a que tales honores extraordinarios tienen un efecto pernicioso sobre el honorando, en concreto generan envidia y conflictividad en su entorno social y político hasta el punto de hacerlo sucumbir víctima de las mismas. En primer lugar, la rivalidad y la conflictividad eran intrínsecas a la vida política de Atenas y no creemos que la concesión de estos honores necesariamente las agudizase; segundo y más importante, el 
pone ante todo de manifiesto el vehemente anhelo de una mayoría del dêmos ateniense de reconquistar el imperio tras el sombrío período que siguió a la derrota en la guerra del Peloponeso, pero pese a la euforia - «dado que Conón ha liberado a los aliados de Atenas», rezaba el considerando del decreto inscrito en el pie de su estatua si creemos una vez más a Demóstenes ${ }^{66}$ - la situación no es sino un espejismo, porque Conón no ha dejado de ser un servidor del Gran Rey -un mercenario de lujo, por emplear las palabras de un ilustre colega español ${ }^{67}$-, bajo las órdenes directas de Farnabazo ${ }^{68}$, y, como tal, ha contribuido -reiteramos que la historiografía griega personaliza en él toda la empresa- a la liberación de las ciudades del yugo lacedemonio para hacerlas independientes o bien ponerlas bajo tutela persa, no para ganar su adhesión a un virtual o futurible imperio ateniense ${ }^{69}$.

En términos prácticos Conón utilizó la fama y prestigio de que disfrutaba para establecer, no necesariamente con el apoyo de Agirrio $^{70}$, un claro dominio en la esfera

mal sobrevenido a Conón en la última etapa de su carrera y de su vida, la prisión temporal que padeció en Sardes, le llegó de la mano de un persa, Tiribazo, el cual, no lo olvidemos -Hamilton lo considera «irrelevante»- fue enseguida desautorizado por su señor Artajerjes (X. HG. 4.8.17).

66 Dem. 20.69. Entusiasmo del que llega a contagiarse algún que otro estudioso moderno: Cloché i919: 169 es un ejemplo.

67 Alonso Troncoso 1999: 64; cf. también Tuplin 1993: 79, que llama a Conón «lacayo persa», y March 1997: 267-269.

68 Un ejemplo claro lo tenemos en X. $H G$. 4.8.6.

69 Deben ser tenidas en cuenta las prudentes advertencias de Seager 1967: 101 y Funke 1980: 118-120 en este sentido. Una nutrida línea historiográfica desde Beloch (véase Sensi Sestito 1979: 25-27, que recoge la literatura anterior, más algún ejemplo reciente, como Buckler 2004: 130-133, 137-139), que de forma un tanto acrítica admite todas las noticias -incluso las más «patrióticas»- de los oradores áticos, ha atribuido a Conón ab initio designios de reconstrucción de la hegemonía naval ateniense, con complicidad satrápica incluida («i piani di Farnabazo .... avevano delle posibilità di successo solo se la flotta, ufficialmente persiana, si fosse presentata di fatto, per la nazionalità del comandante e della parte prevalente degli equipaggi, como una flotta greca», dice la italiana en pág. 26).

70 Como han asumido sin base testimonial Beloch I884: I19-120, Accame 1951: 139, Barbieri 1955: 162 (para quien Conón se integró «nel programa della radical democrazia»), Sealey 1956: 183 y Pecorella Longo 1971: 58, sólo por la inferencia de que Agirrio impulsó su programa demótico basado en el misthòs ekkleiastikós (y también en el theorikón según estos autores, aunque la instauración de éste, y desde luego la organización, pudo ser obra de Eubulo en los años 50) gracias a los fondos persas llevados a Atenas por Conón; para una crítica de tal hipótesis, cf. Funke 1980: 116-117 n. 45 y Strauss 1986: 135. Véase Fornis, Plácido e.p., para la ausencia de pruebas concluyentes de una asociación política, como no fuera circunstancial, entre Agirrio y Conón. 
pública ateniense ${ }^{71}$ y prolongar el eclipse de su principal oponente político, Trasibulo el Estirieo, quien, a tenor del silencio de nuestras fuentes acerca de su persona y su llamativa ausencia de la junta de estrategos de 393/2, «pagó en las urnas» el fracaso de su estrategia continental en Nemea y Coronea ${ }^{72}$. No tardó Conón en limpiar su nombre de toda responsabilidad en la derrota de Egospótamos, a costa de enfangar el de quien fuera entonces colega en la estrategia, Adimanto ${ }^{73}$, mientras aprovechaba para hacer gala de su liberalidad sufragando en el Pireo, en el mismo recinto sacro instituido por Temístocles - nótese la conexión ideológica ${ }^{74}$, la construcción de un templo

71 Besso 1999 ha expuesto que Conón construyó un círculo de «amigos» y «referentes», pese a lo cual «no è esatto affermare che egli agì como leader di un gruppo con un orientamento politico preciso», sino que operaban «come sostenitori di singole iniziative, sfruttando una rete di rapporti personali in grado di sustituirse addirittura allo stato, costituita grazie agli appoggi reciproci tra familigie di un certo rilievo sociale ed economico, secondo uno schema più tradizionale, o a legami nati in occasione di collaborazioni politico-militari.» (cito de pág. I28), pero ¿qué grupo o facción política no funcionaba así -cimentando su actividad en redes de clientelismo, hospitalidad y amistad nuclearizadas por un prostátes con más o menos cháris- en un mundo antiguo que no conoció los partidos políticos tal y como los entendemos hoy en día? Véase también Cox 1998: 25-26 para el uso que hace Conón de conexiones familiares y sociales, particularmente en los demos de Mirrunte y Ramnunte.

72 Trasibulo había sido el arquitecto de la symmachía con los beocios en el verano de $395 \mathrm{y}$, consecuentemente, de una estrategia hoplítica, terrestre, que tenía Grecia central y el istmo de Corinto -lejos por tanto del Egeo- como principales teatros de operaciones (cf. Fornis 2003: passim). Desde el fracaso de esta estrategia continental en las batallas de Nemea y Coronea, en el período que media entre 393 y 390 tan sólo lo menciona Aristófanes (Eccl. 202-204) y es para mostrarle molesto porque no se le pide consejo; poco antes (vv. 193-196) el poeta se hace eco de la ira de un pueblo ateniense frustrado por la escasa efectividad de la prometedora alianza con los beocios, una ira que dirigen contra el anónimo proponente de la misma ante la Asamblea, de seguro un miembro de la facción de Trasibulo. Sobre la caída en desgracia de éste, prolongada por el apogeo de Conón, véase Accame 1951: 98, 100; Sealey 1956: 183; Perlman 1968: 263; Alfieri Tonini 1972: 130; Funke 1980: 266 n. 67; Buck 1998: 104-105.

73 Dem. 19.191. Cf. X. HG. 2.I.32; D.S. 13.106.6; Lys. I4.38; Paus. 4.17.3; 10.9.11. El procedimiento fue la eisangelía o la graphè prodosías; aunque no hay seguridad sobre el veredicto, el contexto demosténico sugiere la culpabilidad (cf. Hamel 1998:148).

74 Auspiciada con tintes propagandísticos por el propio Conón, promotor, en palabras de Funke 1983: I8I, de un «Themistokles Renaissance» (tras un período de cierto olvido de la impronta del vencedor de Salamina) y transmutado él mismo en un «neuer Themistokles» (así ya Cloché 1919: 171). Temístocles había construido un Aphrodísion en ese lugar y existe la posibilidad de que allí también fueron trasladados sus huesos para depositarlos en una tumba monumental (quizá tras la batalla de Cnido y bajo el patrocinio de Conón) desde el lugar secreto del Ática en el que fueron enterrados de forma clandestina por su familia. Los testimonios literarios y arqueológicos, no siempre consistentes, sobre estas construcciones en el puerto «Escarabajo» del Pireo son discutidos por Funke, ibid., 175-189. De hecho Garland 
a Afrodita Euplea («de la feliz navegación», deidad protectora de Cnido), una corona de oro a Atenea y hasta una hecatombe -auténtica, de cien bueyes- y entretenimientos

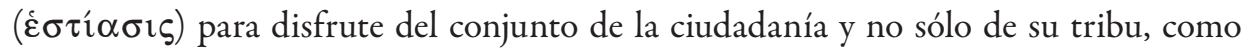
era habitual con las liturgias ${ }^{75}$. Es a estos partidarios del imperialismo ateniense más descarnado a quienes Andócides acusa en el De Pace de querer recobrar el Quersoneso tracio, las colonias, las posesiones y los intereses atenienses en el exterior ${ }^{76}$. Claramente este grupo político se nutría de ciudadanos de las clases más desfavorecidas, que veían en el servicio naval una fuente de subsistencia. Así lo testimonia una vez más Aristófanes en unos conocidos versos de La Asamblea de las mujeres en los que contrapone a los pobres deseosos de sacar las naves a los ricos y terratenientes que se niegan a ello: $v \alpha \hat{v} \varsigma$

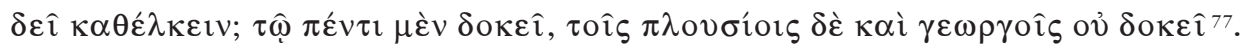
Esta misma idea de que la democracia sólo puede sobrevivir si existe un imperio que la sostenga es recurrente en la oratoria forense ática ${ }^{78}$.

Ahora bien, ¿de esta información debemos inferir que Conón se reintegra plenamente en la vida pública ateniense y deja de ser un asalariado del Rey? Parece harto dudoso. No hay constatación de que desempeñara magistratura alguna que le legitimara para actuar en representación del Estado ateniense -lo que hubiera sido incompatible con su cargo de almirante persa ${ }^{79}$ - y su participación en una embajada oficial ateniense es más que discutible (vid. infra). Como hipótesis de trabajo se podría pensar que Conón actuó en Atenas en calidad de evérgeta que desde su posición preeminente

1987: 150, I54 cree factible que Conón se limitara en realidad a agrandar la estructura existente desde época temistoclea.

75 Paus. I.I.3; Ath. I.3 D; $I G \mathrm{II}^{2}{ }_{1} 424$ a; Dem. 22.72 (= 24.180). Su prodigalidad se habría extendido también a Delfos, donde según Lisias (19.39) donó cinco mil estáteras a Apolo y Atenea.

76 Andoc. 3.15.

77 Eccl. 197-198; también en Pluto (172) Riqueza llena las naves de remeros.

78 Seager 1967: I12 n. I6I cita un número suficiente de pasajes.

79 En tal sentido se expresan, entre otros, Beloch 1884: 314-315, Kounas 1969: 169, Gauthier 1985: 97 y Seager 1967: I0I, del cual extraemos la siguiente cita: «La posición de Conón era contradictoria. Cualesquiera que fueran sus objetivos y logros, él fue a lo largo del período de 397 a 392 un almirante al servicio persa, subordinado a oficiales persas y obligado a defender los intereses persas, en negligencia de los cuales podía ser llamado a rendir cuentas». Contra Singh I971: 125, que afirma sin razonamiento ni base alguna: «he was elected general for the year 393/2» (también Sartori 1973: 336: «rivestiva la strategia»). 
en el ámbito privado, utilizaba la fortuna -tasada en cuarenta talentos ${ }^{80}$-, el prestigio y la influencia derivados de su victoria en Cnido para manejar los resortes del poder y diseñar las líneas maestras de la política ateniense contemporánea.

Desde este momento el esfuerzo bélico de Atenas irá decididamente encaminado a fortalecer su autoridad en el Egeo, en tanto dosifica cada vez más su concurso en la guerra continental. Sin embargo, se ha dicho con ligereza que «la flota cononiana» se convirtió en el instrumento principal de este proyecto de hegemonía marítima, una flota que, antes persa, deviene ateniense al ponerla Farnabazo a disposición de Conón y él retirarse a su corte de Dascilio, cuando la realidad es que nunca existió una flota cononiana, ni siquiera ateniense, antes de que en 39I un intenso programa de construcción naval cimentado en la imposición de tasas a los ciudadanos ${ }^{81}$ permitiera al año siguiente a la Ecclesía poner a disposición de Trasibulo cuarenta trirremes para su expedición al Helesponto.

¿Dónde han ido a parar, pues, las ochenta naves con las que Conón entra en el Pireo? Sin duda Farnabazo, cumplido el efecto escenográfico, le retiró la flota pese a que Jenofonte no lo diga ${ }^{82}$, o bien lo hizo Tiribazo unos meses después, durante su negociaciones con Antálcidas en Sardes, cuando además apresó a Conón bajo la acusación de utilizar la flota para sus propios fines, identificados con los de Atenas. El caso es que nunca estuvieron a disposición del estado ateniense ${ }^{83}$. Es un error muy extendido entre la historiografía moderna dejarse llevar por las fuentes antiguas y considerar la

\footnotetext{
80 Lys. 19.39-40.

8I Lys. 28.4.

82 Así también Shrimpton I991: 4, para quien a finales de la estación de campaña de 393 Evágoras disponía de su flota, instrumental en sus planes de conquista sobre el resto de Chipre, mientras las naves fenicias, tirias en su mayor parte, habrían regresado también a casa; cf. Maffre 2004: 17: «les événements militaires navals des années postérieures [393] confirment que la flotte achéménide a été débandée, seules s'affrontant les flottes lacédémoniennes et athéniennes sans financement perse». Según Barbieri 1955: I7I, Farnabazo no habría dejado en manos de Conón la flota completa, sino sólo las naves «griegas», esto es, chipriotas.

83 Como por ejemplo presumen Hamilton 1979a: 290, que llega a afirmar que los eufóricos atenienses se lanzan a la conquista de un nuevo imperio, Funke: 134 n. 94 y Clark 1990: 58.
} 
flota persa bajo Conón una flota ateniense que no sólo libera Asia Menor, sino que reanuda la actividad imperial de antaño ${ }^{84}$.

Sea como fuere, desde este momento de éxtasis popular Atenas caminará sola, económicamente hablando. Aunque la colaboración con Persia se mantiene nominalmente -claramente la práctica desaparición de la presencia lacedemonia de tierras asiáticas era en sí mismo un objetivo alcanzado desde la óptica persa-, no oímos de más subvenciones y eso sin duda debió de pesar sobre el dêmos a la hora de ponderar el futuro de dicho compromiso y, si es necesario, sacrificarlo.

En esta voluntad - por el momento no es más que eso, un proyecto, una expectativa ${ }^{85}$ - de reconstrucción imperial auspiciada por Conón, que se diferencia nítidamente de la estrategia continental abanderada por Trasibulo en los preámbulos de conflicto ${ }^{86}$, se inscribe un posible intento de «cortejar» políticamente al poderoso tirano Dionisio de Siracusa, proclive a los lacedemonios ${ }^{87}$, a quien la Boulé ateniense honra-descono-

84 Véase por ejemplo cómo Cloché 1934: I9 habla de Conón: «Enfin l’influence athénienne se propage largement dans la mer Égée : exploitant au bénéfice de sa patrie l'œuvre strictemente libératrice accomplie en 394»; la inevitable consecuencia es caer en el sinsentido de concebir un imperio ateniense dentro del imperio persa: «ainsi s'ébauche, au seuil de l'empire perse, une confédération dont Athènes paraît prête à guider les destinées» (pág. 20). Incluso un partidario de la idea de que Atenas no desarrolló conductas imperialistas a lo largo del siglo IV como Phillip Harding (1995) considera a Conón y a Trasibulo «hangovers from the fifth century» (cito de pág. II 4 ).

85 Ha sido Robin Seager (1967) el estudioso que, bajo nuestro punto de vista, mejor ha captado e interpretado la situación que se vivía en la Atenas de esos momentos a la luz de las fuentes disponibles y sin forzarlas a decir lo que no dicen, una recomendación que siempre recordaba el maestro Édouard Will. Naturalmente la posibilidad de recuperar el imperio del siglo V no depende únicamente del sentimiento de la ciudadanía ateniense (a la sazón inequívoco), sino de los medios de que se dispone para llevarlo a cabo. Poética resulta la metáfora de Ernest Badian (1995) en la que, cada vez que Atenas remonta, o parece remontar, a una posición de privilegio en el concierto internacional del siglo IV, el fantasma del imperio perdido hace su aparición y se va apoderando de quien o quienes lo convocan - «the necromancers who gained the trust and the votes of the Demos» y, por extensión, de la ciudadanía misma-, con su exigencia de sangre, es decir, de un esfuerzo más allá de las posibilidades reales del pueblo ateniense y por ello siempre abocado al desastre, hasta que el fantasma ha succionado por fin toda la sangre y lleva al cuerpo (cívico) a un colapso final que llegaría con la derrota en la guerra lamíaca.

86 Vid. supra n. 72.

87 En el discurrir de las tradicionales relaciones de amistad, si no de alianza, entre el tirano siracusano y los lacedemonios desde los momentos finales de la guerra del Peloponeso, Anello 1996: 405-407 vislumbra un cierto enfriamiento entre 398 y 393 , breve período en el que la italiana sitúa ciertos hechos de neblinosa cronología susceptibles de ser interpretados como lesivos para Esparta (como el intento de 
cemos con qué honores o privilegios debido al mal estado de la piedra, pero es significativo que se le denomine arconte o gobernante (ó $\rho \chi \omega v)$ de Sicilia- junto a sus hermanos Teárides y Leptines, a su cuñado Políxeno y acaso a algún familiar más en una moción aprobada a comienzos de 393 -a propuesta de Cinesias, poeta ditirámbico satirizado por los $\operatorname{cómicos}^{88}$ - e inscrita en una estela de mármol pentélico con un relieve de Atenea sosteniendo en su mano derecha a la personificación de Sicilia ${ }^{89}$.

asentamiento en Mesene de los mesenios expulsados de Naupacto y de Zacinto [D.S. I 4.7 8.5; cf. 34.2-3], la hospitalidad durante su exilio y más tarde el apoyo activo a la restauración del rey moloso Alcetas, cuya dinastía mantenía estrechos vínculos con Atenas [D.S. 15.13.2-3]) al que habría puesto fin el restablecimiento del entendimiento entre persas y lacedemonios. Cf. también Giuliani 1994: 157-158.

88 Ar. Eccl. 329-330; Ra. I 437; Av. 1372-1 409. El cómico Estratis llegó a poner su nombre a una comedia de

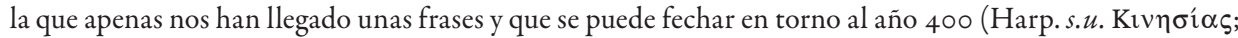
Ath. 55Id).

$89 I G \mathrm{II}^{2}{ }_{18} 8=\mathrm{S} I G$ I28 $=S G H I \mathrm{n}^{\circ}{ }_{10} 08=G H I \mathrm{n}^{\circ}$ I0. Se trata de una resolución presentada en la sexta pritanía del arcontado de Eubúlides (394/3), por tanto en enero o febrero de 393, que no pasó posteriormente a la Ecclesía para su conversión en pséphisma (presumiblemente por la respuesta negativa del Dinoménida). En su comentario a la inscripción, Marcus Tod señala que Leptines y Teárides aparecen en las fuentes literarias colaborando estrechamente en el gobierno de su hermano -al que una inscripción oficial de la democracia ateniense lógicamente no puede llamar tirano-, generalmente en calidad de almirantes de la poderosa flota siracusana, lo mismo que Políxeno, quien, además de almirante (dirigió la escuadra de veinte naves enviada en ayuda de los lacedemonios en 387 : X. HG. 5.1.26), ejerció de embajador y consejero. Dado que el proponente es un conocido poeta ditirámbico, que la moción fue pasada poco antes de la celebración de las fiestas Leneas, que la estela fue erigida en el teatro de Dioniso y que el tirano siracusano era un amante de la poesía, se ha pensado que el motivo de los honores podía tener relación con las representaciones teatrales. De ser así, esto no estaría reñido con el reseñado objetivo de captar la benevolencia política de Dionisio el Viejo. Sobre la hipotética, mas indemostrable, vinculación de Cinesias con Conón, véase Cloché 1919: 168 y 1934: 19; Beloch 1922: 79; Treves 1937: 131 n. 3; Meloni 1950: 304; Barbieri 1955: 167; Strauss 1986: 134; ha sido puesta en duda por Seager 1967: 103 y Funke 1980: I06 n. I3. Siracusa contaba con un más que notable poderío naval que encajaría bien en el proyecto de imperio ultramarino pergeñado por Conón y no tanto en el de Trasibulo, quien atado por el momento a sus aliados continentales no asumirá los presupuestos de una estrategia naval hasta la muerte del de Anaflisto y el fracaso de las negociaciones de paz de 392. Pese a ello, Accame 1956: 517, seguido por Saur 1978: 238 (sin citarlo), ve en Trasibulo al promotor de este acercamiento diplomático a Siracusa en virtud de unos cuestionables ideales panhelénicos que llevarían al Estirieo a tender lazos con el helenismo occidental. En realidad, como bien recuerda Funke 1980: II2 n. 27, nuestra ignorancia acerca de la actividad política de Cinesias, más allá de este decreto, es absoluta. Desde el punto de vista siracusano Sanders 1987: 10-I 4 ha indicado que esta aproximación (no sólo política, también cultural, pues el autor sugiere que el tirano utilizaría instrumentalmente a los literati atenienses para su propaganda imperial) fue posible por la paz suscrita entre Siracusa y Cartago tras la derrota de esta última en 396 y por la actividad 
Parece así mismo que Conón trató de emparentar a Dionisio y Evágoras de Salamina a través de una alianza matrimonial que, en una filigrana diplomática, ganaría al primero para la causa de Atenas ${ }^{90}$. Ambas maniobras resultarían fútiles y no evitarían la decisiva ayuda naval que el tirano proporcionó a los espartanos unos años más tarde ${ }^{91}$.

Un pséphisma ateniense de 393, éste sí votado en la Ecclesía, honra al rey chipriota Evágoras de Salamina, valedor de Conón en sus días de desgracia, que ya recibiera la ciudadanía ateniense en $41^{92}$ y que ahora ve erigida su estatua en un lugar central del ágora de Atenas, al lado de la de Zeus Eleuterio y de la del propio Conón, cerca del pórtico real ${ }^{93}$.

de un «partido filosiracusano» en Atenas al que se opondría otro «antisiracusano» (la terminología es inapropiada y refleja un enfoque errático de la política interna ateniense).

90 Lys. 19.19-20.

91 D.S. 15.23; Lisias (ibid.) atribuye un cierto éxito en su misión a Aristófanes y Éunomo, colaboradores

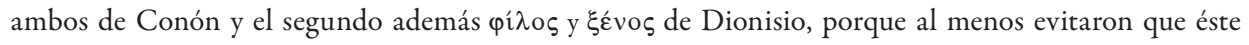
enviara las naves a los lacedemonios; en realidad fue sólo una demora (como sabemos por X. HG. 5.I.26 y 28 el tirano envió veinte naves a Antálcidas en 388/7) cuya razón ha de verse en la reanudación de las hostilidades contra Cartago (cf. Funke 1980: I31; Anello 1996: 407-408 reconoce el peso de este argumento, pero no descarta que Dionisio pretendiera realmente una aproximación a los atenienses ante el deterioro que, en opinión de esta autora, sufrían sus relaciones con Esparta). Pese al fracaso, Treves 1937: I3I ve en Conón al heredero de Pericles por su «geniale concepimento e vastità di visione». Extrañamente Brun 2005: $\mathrm{n}^{\circ} 37$ considera fructífera la iniciativa, que según él se habría materializado en un tratado de alianza (del que no hay testimonio alguno) que habría normalizado las relaciones entre Atenas y Siracusa veinte años después del fracaso de la expedición a Sicilia de 415-413 y que habría impedido la llegada de trirremes sicilianos a la flota lacedemonia. En realidad las relaciones entre ambos estados no mejoraron hasta después de la batalla de Leuctra, cuando los atenienses dieron un giro a su política exterior para aproximarse a los lacedemonios, aliados naturales de Dionisio ( $S G H I \mathrm{n}^{\text {os }} 133$ y 136).

$92 I G \mathrm{I}^{3}$ I13; Dem. I2.IO; Isoc. 9.54. Sobre el contenido de esta inscripción, en estado muy fragmentario, véase Costa 1974: 45-46 y Osborne 198I: 3I-33 y 1982: 2I-24 (éste la data a comienzos de 407).

93 A la lectura y restauración del primer fragmento $\left(I G \mathrm{II}^{2} 20=S G H I \mathrm{n}^{\circ}{ }_{109}=G H I \mathrm{n}^{\circ} \mathrm{II}\right)$, que pasará a ser designado como c) de acuerdo con el orden original de la estela, Lewis y Stroud 1979 añadieron dos más inéditos, el a) y el b), a la vez que proponían una nueva interpretación para el c). Aunque dichos autores dudan entre atribuir la inscripción al arcontado de Eubúlides (394/3) o al de Demóstrato (393/2), reafirman su conexión con Conón -hubiera éste ya regresado a Atenas o estuviera a punto de hacerlo- y, en lo sustancial, su principal aportación es que, entre los honores extraordinarios conferidos a Evágoras, el "E $\lambda \lambda \eta \nu$ de la línea 17 los inscriben en un elogio del monarca como un «heleno». Cf. Isoc. 9.57; Paus. I.3.I.

$\mathrm{DHA}_{34 / 2}-2008$ 
Sófilo, proponente de este decreto y miembro a lo que parece del círculo de Conón, es también el promotor de otro pasado en $394 / 3$ en el que se concede primero la proxenía y la evergesía y a continuación, como enmienda, la ciudadanía ateniense a Fil[........ -es de Rodas, quizás por su conexión con la revolución democrática de la isla en el verano de 395 , que puso las bases de una firme alianza con Atenas ${ }^{94}$. Y todavía dos decretos más fechados en el mismo arcontado y sin duda alguna relacionados con los anteriores, como bien han visto Michael Osborne y Peter Funke, conceden la ciudadanía ateniense, la continuidad del $\mu \iota \sigma \theta o ́ s$ que percibe de los estrategos e invitación a $\delta \in \hat{\imath} \pi v o v$ en el Pritaneo al vidente Estoris de Tasos, por haber desplegado su mántica en relación con ${ }^{1} \dot{\eta}$ vavuaxía, que obviamente sólo puede ser la de Cnido"s.

Distinto es en cambio otro decreto de la Asamblea ateniense que hasta no hace

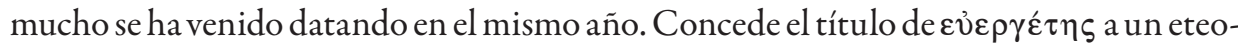
carpaciano, a sus hijos y a todo el koinón de los eteocarpacianos, de la isla de Cárpatos, en agradecimiento por haber proporcionado cipreses del recinto sacro de Apolo para la reconstrucción del viejo templo de Atenea, pero lo que es más importante, el dêmos ateniense garantiza la independencia de la comunidad eteocarpaciana, retira la guarnición de su Acrópolis e insta a los habitantes de Cos, Cnido, Rodas y el resto de los aliados de la región a prestarles ayuda según las posibilidades de cada uno. Tal y como

$94 I G \mathrm{II}^{2}$ 19; cf. Osborne 1981: 42-43 y 1982: 43-45; Funke 1983: 152-163; Besso 1999: 125-126.

$95 I G \mathrm{II}^{2} \mathrm{I} 7+S E G$ 15.84; cf. Osborne 1970, 1981: 43-45 y 1982: 45-48, con nueva lectura y completo comentario crítico; Funke, ibid. De la notabilidad alcanzada por Estoris dice mucho que hacia $389 / 8$

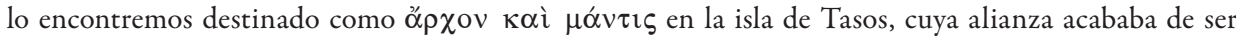
recuperada por Trasibulo de Estiria, a petición de los propios tasios $\left(I G \mathrm{II}^{2} 24\right)$; su solvencia económica también está más allá de toda duda a juzgar por el hecho de que costea las dos estelas que se erigen en la Acrópolis y en el santuario de Apolo (y al menos la que se ha preservado de diseño típicamente tasio). Funke 1983: 164-174 no ve empero argumentos solventes para situar en este contexto histórico y político otros dos controvertidos epígrafes fragmentarios: el primero es una concesión de proxenía ateniense a un ciudadano rodio cuyo padre ya fue próxeno ateniense en Yaliso con anterioridad a la defección rodia del imperio ateniense en 412/1 y al sinecismo de 408 ( $S E G$ 28.48; la datación fue sugerida por Woodhead 1948: 54-57), pero que parece encajar mejor en la reanudación y normalización de las relaciones diplomáticas con la isla tras la revuelta democrática en 395, y el segundo una concesión de honores a ciudadanos atenienses, metecos, extranjeros y esclavos que combatieron en ocho trirremes durante la guerra jónica ( $I G \mathrm{I}^{3} \mathrm{I}$ O32) y que Laing 1965 creyó identificar con las ocho que huyeron a Chipre con Conón después de la derrota de Egospótamos, de modo que sus tripulaciones regresarían años más tarde a Atenas junto con su comandante para recibir el reconocimiento público. 
advirtió Cloché en su momento, «le décret ne semble pas dépourvu d'un certain esprit impérialiste, encore contenu, mais perceptible» ${ }^{96}$. Efectivamente estas «bondades» son una gracia, una expresión de la voluntad del dêmos ateniense, lo que excluye una relación de igualdad entre ambos estados; de hecho la inscripción recoge que si alguien ofendía al koinón o dañaba la estela, debería pagar una multa de cincuenta talentos a la comunidad eteocarpaciana y una décima parte a la diosa Atenea, siendo los tesmotetas atenienses los competentes en el juicio. Dicho de otra manera, Atenas se encuentra aquí en un plano de superioridad con respecto a sus aliados, no hay rastro del principio de igualdad que regía los tratados con locros y eretrios ${ }^{97}$ y sí en cambio de los viejos mecanismo imperiales del siglo V. Como han argumentado Lewis, Funke y Strauss, estos importantes matices arrojan fuertes sospechas sobre una datación en estos años y hacen preferible llevar la inscripción a los años 40 ó 30 de la centuria anterior, como de hecho se recoge ya en la tercera edición de $I G^{98}$.

96 Cloché 1919: 169.

$97 I G \mathrm{II}^{2}{ }_{15}=S G H I \mathrm{n}^{\circ}{ }_{102}=$ Staats. $\mathrm{n}^{\circ} 224$ (locros); $I G \mathrm{II}^{2}{ }_{16}+S I G{ }_{12} 3=S G H I \mathrm{n}^{\circ}{ }_{103}$ (eretrios).

$98 I G \mathrm{I}^{3} 2.1454$ (editado por David Lewis y Lilian Jeffery en 1994), que rectifica y sustituye a $I G$ XII I.977 $=S I G \mathrm{n}^{\circ}{ }_{129}=S G H I \mathrm{n}^{\circ}{ }_{110 .}$. Cf. Lewis 1977: 144 n. 55; Funke 1980: 133 con n. 92; Strauss 1986: 445 n. 29. Recordemos que el koinón eteocarpaciano había sido tributario de Atenas en el siglo V. Tod (SGHI $\mathrm{n}^{\circ}$ IIO) fechó la inscripción con seguridad entre 394 y 390 , en primer lugar porque Cos hizo defección de Esparta tras la batalla de Cnido y por el año 390 la propia Cnido había vuelto a la alianza lacedemonia y, en segundo lugar, porque asociaba los trabajos de reconstrucción en el templo de Atenea con el incendio que sufrió en 406/5, mencionado por Jenofonte; desde entonces esta datación ha sido mayoritariamente favorecida por los estudiosos. Pero además de Lewis, Funke y Strauss, a los que nosotros seguimos aquí, hay dos excepciones más. La primera es Seager 1967: 102 n. 66, 109, que trató de salvar este escollo y retrasar el terminus ante de la inscripción hasta 389 , dando pie a la posibilidad de que la injerencia ateniense en Cárpatos se inscribiera en la última campaña de Trasibulo; su argumento de que, incluso en manos espartanas, Cnido habría sido mencionada «en beneficio de la moral ateniense» es en nuestra opinión endeble, no obstante lo cual Funke (ibid.) considera que esta hipótesis ofrece una alternativa a la datación en el siglo $\mathrm{V}$ «al enlazar la política de Trasibulo con el viejo imperio ático». La segunda es Dinsmoor 1940: 179 n. 2, quien llevaba la inscripción a 377, pero como también aduce Funke (ibid.) con buen criterio, Atenas no hizo uso de prácticas imperialistas como establecer guarniciones, arrogarse jurisdicciones en materia judicial o exigir diezmo para la diosa Atenea durante la primera fase de la segunda liga naval. La improbable datación del decreto eteocarpaciano en la década del 390 lleva a ciertos autores como Griffith 1978: 130-132 a suponer que Atenas impuso guarniciones por doquier en los territorios aliados. 
Aunque no faltan dudas tampoco, sí parece corresponder al período inmediatamente posterior a la batalla de Cnido el envío a Persia de la embajada encabezada por Epícrates y Formisio, quienes reciben presentes del Gran Rey y sin duda consolidan la relación de amistad y cooperación entre ambos poderes 99 . Tanto el despacho de esta legación como los decretos emanados de la Boulé y la Ecclesía honrando a individuos próximos a Conón responden a idéntico clima político y sirven de elocuente confirmación sobre las expectativas creadas entre el dêmos ateniense durante aquellos meses ${ }^{100}$.

De forma paralela a esta intensa actividad diplomática, Conón prosigue la ofensiva naval en la primavera de 392 con una campaña más «en las islas y ciudades costeras de Asia Menor» de la que apenas tenemos información, pero que a buen seguro, a tenor de los sagaces alegatos contemporáneos de los lacedemonios ante Tiribazo acerca de cómo los atenienses empleaban el dinero persa en su propio beneficio, podía interpretarse con una restauración de la influencia ateniense en estas zonas. Ahora bien, un control firme, un dominio ateniense, sólo está constatado fehacientemente en las islas

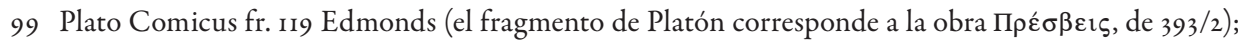
Ath. $25 \mathrm{I}$ a-b, que cita a Hegesandro. Los regalos aceptados por los embajadores dieron pie a rumores, puede que traducidos en acusaciones formales de soborno (habituales siempre que un griego es agasajado por el Rey), pero la continuidad de la influencia de Epícrates y el pasaje de Ateneo indican que o bien ni siquiera llegaron a juicio o bien fueron absueltos (cf. Bruce 1966: 277-278; para Strauss 1986: 136 la persecución «might have come less from any misdeeds of theirs than from a basic hostility to Persia»). Si el sujeto del Contra Epicrates (XXVII) de Lisias es, como creemos, nuestro Epícrates, el de Cefisia, en el discurso se alude ( 3 y 6-7) a una ocasión previa en que fue juzgado y absuelto del delito de soborno y bien pudo ser ésta de la embajada a Persia junto a Formisio (cf. Wilamowitz-Moellendorff 1921: 736; Davies 197I: I8I; Strauss 1985: 68 n. 3 prefiere dejar la cuestión «en suspenso» por las dudas sobre la identidad del personaje). La fecha es incierta, pero probablemente el mejor momento es justo después de la batalla de Cnido: Treves 1937: 128, Bruce 1963: 290-291 con n. 13 y 1966: 277-278; Davies 1971: 181 (o bien 393/2); Perlman 1976: 230; Hamilton 1979a: 217; Funke 1980: 106 con n. 12; Strauss 1986: 126; Develin 1989: 209 (con dudas); para Seager 1967: 103 n. 2 y Cook 1981: 348 sería algo más tarde, tras el retorno de Conón a Atenas; Meyer 1909: 54, Wilamowitz-Moellendorff I921: 735-736 y Beloch 1922: 84 la llevan al año 39r y Cloché 1960: 8r incluso al final de la guerra (aunque Cloché 1934: I9 la asociaba al retorno de Conón en 393), mientras según Saur 1978: 236-237 sería antes, en el verano de 395, como uno más de los contactos previos al estallido del conflicto.

I00 Funke 1983: 162. A este momento de máximo prestigio e influencia de Conón podría corresponder igualmente el nombramiento de Trasibulo de Colito como anfictión ateniense en Delos ( $\left.I G \mathrm{II}^{2}{ }_{1} 634\right)$, aunque no hay certidumbre sobre la alianza política entre ambos. Más aventurado es atribuir a Conón en 393/2, como hace Strauss 1986: 129, el patrocinio de una embajada a Quíos en la que Isócrates colaboraría en la preparación de un ordenamiento democrático y que habría molestado a Persia (Plu. Mor. 837 B). 
de Lemnos, Imbros y Esciro, antiguas cleruquías localizadas en la vital ruta de importación de grano y en sí mismas con una nada despreciable producción de éste ${ }^{\mathrm{ror}}$, que vemos en poder de Atenas durante las negociaciones de paz del siguiente invierno ${ }^{102}$. Con la adquisición, dominación y explotación de territorios, el rasgo más evidente de un comportamiento de cariz imperialista, puede afirmarse que comienza a tomar forma la idea de imperio avalada por Conón. Por el contrario, conforme el principal teatro de operaciones se traslada al istmo de Corinto y al Egeo, lejos de sus tradicionales intereses en Grecia central, los beocios pierden progresivamente entusiasmo y por el año 392 se muestran proclives a negociar la paz $^{103}$. De los otros dos aliados, Corinto tenía suficiente con mantener su integridad bajo una situación de stásis permanente, con la fortaleza del Acrocorinto y otras partes de su territorio ocupadas por fuerzas extranjeras, mientras Argos centraba todo su interés en mediatizar la política interna corintia ${ }^{104}$.

IOI Cf. Seager 1966: 172, que da las fuentes.

102 X. HG. 4.8.12; D.S. 14.85.4. Según Seager 1967: 102 n. 66, seguido por Strauss 1986: 129, la empresa no comportó necesariamente una acción militar, pues los lacedemonios habrían evacuado las islas después de la batalla de Cnido y los antiguos clerucos atenienses, que no habían sido expulsados al finalizar la guerra del Peloponeso, facilitarían el restablecimiento de estrechos lazos con la metrópolis. Sin explicación alguna, Buckler 2004: 4-5 afirma que Esparta permitió a Atenas retener el control de estos enclaves en 404 .

103 Cook 1981: 352 sospecha que el renacimiento de las pretensiones imperiales de Atenas generó inquietud en Beocia y la facción de Ismenias perdió fuerza, aunque no el control de los asuntos públicos. Juicio opuesto es el de Pascual González 1995: 827, quien parece ver más ventajas que inconvenientes en el nuevo rumbo de la guerra, ya que, si bien reconoce el escaso interés beocio más allá de Grecia central y el Noroeste, «Beocia se veía libre de las invasiones espartanas, el ejército federal no sostiene sobre sus escudos el peso principal de los combates con lo que las bajas disminuían apreciablemente y la ayuda financiera persa contribuía a hacer más llevadero el esfuerzo bélico. Debido a todo esto y a las victorias de Conón y Farnabazo y de los corintios en el Golfo, la facción de Ismenias debió verse algo aliviada y estaba dispuesta, aún, a continuar la guerra».

104 En Fornis 2001 mostramos por un lado el caos y la desestructuración institucional padecida por Corinto durante estos años y a la vez defendimos que lo que Jenofonte, portavoz de la clase privilegiada corintia expulsada del poder, presenta como una pérdida de identidad, de soberanía e incluso como una absorción del estado corintio por el argivo, fue en realidad parte de esa lucha faccional que llevó al poder a un grupo argolizante respaldado por la guarnición argiva en Corinto, con lo que no hubo ni sinecismo, ni isopolteía, ni sympoliteía, ni isoteleía, ni ningún otro tipo de experimento político imaginado por los historiadores modernos. 
Pero no sólo los beocios cedían en su beligerancia. Diversas razones de índole interna promueven un giro en la política exterior espartana, hasta entonces eminentemente belicista, que coincide en el tiempo, y no por casualidad, con la sustitución de Titraustes por Tiribazo en la satrapía de Lidia y en la dignidad de káranos ${ }^{105}$. En la primavera de 392 Antálcidas, un prominente espartiata que, además de gozar de la simpatía y la confianza de Tiribazo, tenía importantes vínculos familiares entre la aristocracia persa ${ }^{106}$, viaja a Sardes para intentar convencer a Tiribazo de que su señor Artajerjes II está financiando la reconstrucción del imperio ateniense -que en la centuria anterior incluía Jonia y el Helesponto-, y a la vez de que Esparta no cuestiona la

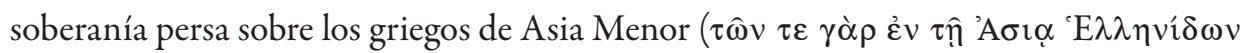

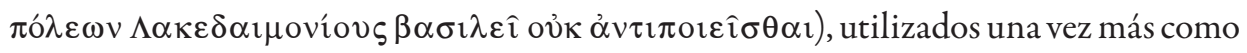
moneda de cambio en las relaciones con el Gran $\mathrm{Rey}^{107}$, mientras el resto de las ciudades griegas del continente y de las islas, inmersas o no en el conflicto, habrían de perma-

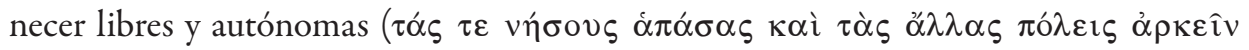

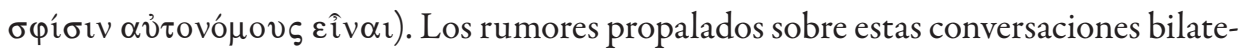
rales entre espartanos y persas celebradas en Sardes atraerán pronto delegaciones de los estados que conformaban el sinedrio de Corinto, inquietos por la posibilidad de quedar al margen de potenciales acuerdos o de perder a Persia como aliado. No es extraño que los atenienses pensaran en Conón, símbolo palpable de la relación entre su polis y los persas, para acompañar e introducir en la corte satrápica a la embajada oficial que representaba al Estado ateniense, de la que él, por obvio conflicto de intereses, no podía

I05 X. HG. 4.8.12; D.S. I 4.85.4; cf. X. HG. 4.2.13 y Ages. I.Io. Las razones de tal cambio de orientación han sido expuestas en Fornis 2005: 270-27I.

I06 Era xénos hereditario de Ariobarzanes y hasta el propio Artajerjes lo trataba como húesped y amigo (X.HG. 5.I.6 y 28; cf. Plu. Art. 22.6 y Pelop. 30.6). Las fuentes y la bibliografía sobre Antálcidas están recogidas en Hofstetter 1978: $\mathrm{n}^{\circ}$ I8 (pp. 15-16).

I07 La libertad de los griegos asiáticos estuvo siempre a merced de la Machtpolitik ejercida por las potencias hegemónicas griegas, como hemos puesto de manifiesto en Fornis 2006. 
ser integrante ${ }^{108}$. Prueba de ello es que, tras el fracaso de las negociaciones ${ }^{109}$, Tiribazo ordena arrestar a Conón -«como si hubiera cometido una injusticia contra el Rey» ( $\dot{\omega} \varsigma$ $\dot{\alpha} \delta \imath \kappa о \hat{v} v \tau \alpha \beta \alpha \sigma \imath \lambda \hat{\varepsilon} \alpha)^{\text {ro }}$-, que, como oficial persa que aún era, estaba sometido a su

Io8 No hay prueba o testimonio de que Conón ostentara alguna magistratura ateniense durante su estancia de unos meses en la ciudad, lo que confirmaría que desde su elección en 397 hasta su muerte en 392 ó 391 no dejó en ningún momento de ser un almirante persa (pace Barbieri 1955: 171, que ha planteado que Conón fue «ammiraglio persiano più di fatto che di diritto»). Su vínculo con el Gran Rey entra, pues, en franco conflicto de intereses con una hipotética participación en la legación ateniense que viajó a Sardes a negociar la paz. Por esta razón creemos que Conón acompañó a título privado a los embajadores oficiales, para facilitar en la medida de lo posible su labor en la corte persa (así entiende Aucello 1965: 346

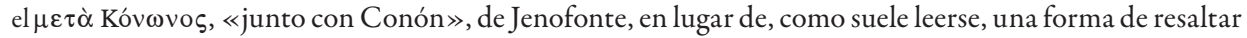
la figura de Conón o incluso una posible presidencia de la embajada. En parecidos términos Kounas 1969: 169; Costa 1974: 52; Funke 1980: 137 n. 8 y Jehne 1991: 267 n. I 4; por el contrario Mosley 1973: 17-18, Saur 1978: 221, Strauss 1986: I37 con n. 58, Bianco 1994: 21 o Buckler 2004: I 4I no consideran un conflicto de intereses servir al Gran Rey y mirar al tiempo por el bienestar de Atenas, cosa que podría ser aceptable si no habláramos de representaciones diplomáticas; curiosamente Besso 1999: I2 I n. 33 admite que en efecto se trataría de una contradicción, pero que precisamente le haría «perdere credibilità agli occhi persiani»). Otras soluciones al problema de la incompatibilidad resultan menos satisfactorias, como por ejemplo pensar que la embajada no tuviera un carácter oficial (Urban 1991: 62, seguido por Buck 1994: 50 y 1998: 109 con n. 15). Esta indefinición da cobertura a afirmaciones como la de Meloni 1950: 304 : «Conone, oramai più stratega ateniese che ammiraglio persiano».

Los miembros de la embajada ateniense fueron Dion, Calístenes, Hermógenes y Calimedonte, que nos resultan poco o nada conocidos a través de otras fuentes (de Dion se ha dicho que puede ser el orador mencionado junto con Arquino en Pl. Mx. 234 b; otro pasaje de los diálogos platónicos, en esta ocasión Cra. 384 a-b, se refiere a un Hermógenes hijo de Hipónico, quizá hijo a su vez del Calias que negoció hacia 449 la paz con Persia que lleva su nombre, con lo que pertenecería a una de las familias más rancias y ricas de Atenas, del linaje de los Cérices y custodia de la proxenía espartana de forma hereditaria [X. $H G$. 6.3.3-4]; sobre Calimedonte Ath. [340 e] lo vincula a la familia de Agirrio), lo que no es razón suficiente para dudar de la historicidad de la embajada (tal y como hizo Jacoby FGrH III b [Supp.], II [Notes], 417, quien aducía además la presencia de Conón para considerar apócrifa la embajada), pues, como ha demostrado Mosley (ibid., I8-20) aportando varios ejemplos, la continuidad en la representación de la ciudad no es precisamente una característica de la práctica diplomática ateniense y existe constancia cierta de no pocos embajadores de los que tan sólo conocemos el nombre. Realmente parece una insensatez que Jenofonte hubiera inventado una embajada, citando incluso por el nombre a sus integrantes, cuando muchos de sus lectores tenían vivo aún el recuerdo de los acontecimientos. Como apostilla este mismo autor, Jenofonte puede ser con frecuencia acusado de distorsión o presentación selectiva de los hechos más que de «fabricación».

I09 Hemos abordado el asunto con detalle en Fornis 2005.

i 1 O Según D.S. I 4.85.4, el cargo contra él era por uso indebido de la flota del Rey para poner a las ciudades

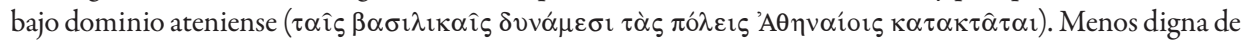
crédito, excepto para Kounas 1969: 170 y Strauss 1986: 137, es la noticia del Sículo de que Tiribazo se dejó guiar 
autoridad, mientras no se puso obstáculo a que los embajadores atenienses regresaran a su patria. Huido o liberado pronto de su cautiverio, Conón se retiró a la corte del monarca filoheleno Evágoras de Salamina, donde enfermará y morirá poco después ${ }^{11}$.

A juzgar por el desencanto y la crítica hacia Conón que transpira el Epitafio en honor de los caídos en la guerra de Corinto que Lisias redactó por este tiempo, en 392 ó 39I, así como por sucesivos acontecimientos, la directriz política que arropaba la idea de colaboración con Persia había fenecido con su máximo adalid ${ }^{112}$. Se cerraba así una fase de la guerra de Corinto y un ciclo, por breve que pueda parecer, de la propia historia ateniense, un período marcado por un incipiente y aún desdibujado proyecto de reconstrucción imperial ateniense al calor del entendimiento con Persia. La desaparición de Conón supondrá la reaparición con fuerza de Trasibulo en la escena política, de la que se había visto marginado por los triunfos de su antagonista político, que no personal ${ }^{113}$. El Estirieo retomará con nuevos bríos y mayor decisión la idea de reconstrucción imperial, sólo que con una notable diferencia: la enajenación de la amistad

también por motivaciones personales, concretamente la envidia hacia un Conón que había ganado el favor del Rey.

III Lys. 19.39-44 y Dinón apud Nep. Con. 5.3-4, preferibles a Isoc. 4.154 y D.S. 15.43, donde Conón es ejecutado por los persas. Incomprensiblemente Jenofonte no dice nada acerca de la suerte final de tan relevante personaje. Treves 1937: 131, Accame 1951: I19 y Barbieri 1955: 187, 192 creen que no intentó volver a Atenas porque entendía que su política imperial sustentada en el apoyo de Persia había fracasado y no quería precipitar la ruptura con ésta, aunque quizá simplemente no le dio tiempo antes de caer enfermo. Todo depende de si Conón llegó a conocer la noticia de que Artajerjes no sancionó la política de Tiribazo y lo sustituyó por el filoateniense Estrutas.

II2 Seager 1967: 100, 108; Strauss 1986: 135; Bianco 1994: 24. Efectivamente la figura de un Conón innombrable es oscurecida: Cnido es descrita como una victoria de bárbaros sobre griegos y hasta la reconstrucción de los muros llamados «cononianos» son obra de los hombres de File, los auténticos patriotas (Lys. 2.59 y 63).

II3 Con argumentos poco consistentes y desarrollando una idea que ya está presente en Beloch i884: I19 y Barbieri 1955: 172, Strauss 1984 ha extendido al terreno personal la rivalidad política entre los dos grandes protagonistas de la historia ateniense de la primera década del siglo IV, Conón y Trasibulo; así, el historiador estadounidense ve indicios de esa supuesta animadversión mutua en que según Aristóteles (Rh. I 400 b 20) el primero llamó al segundo hombre «de osado consejo» (que por otra parte es lo que significa su nombre: thrasys boulé), en que este último mostró su adhesión hacia Alcibíades y sirvió con él durante la guerra jónica en tanto que Conón no lo hizo y, por último, en la prominencia misma de ambos, que hacía que Atenas, según Strauss, «was not big enough for two liberators». Cf. Funke 1980: 126 n. 67 , que ya manifestaba que tal enemistad « ist nicht zu entscheiden ». 
persa, incompatible con un dominio ateniense en el Egeo y la costa minorasiática. Su expedición al Helesponto, que supuso la cristalización de un imperialismo ateniense hasta entonces sólo esbozado -coerción para engrosar la nómina de aliados, extorsión y depredación de los ya existentes-, demuestra que, en contra del empeño de buena parte de la bibliografía moderna ${ }^{114}$, Trasibulo no era más «moderado» que Conón en su concepción de la política imperial ${ }^{115}$.

II4 Muy especialmente Silvio Accame en 1951: I28-129, 135-139 y sobre todo en 1956, que presenta a Trasibulo como el patrocinador de un ideal panhelénico «sulla base di alleanze a parità di diritto per cui Atene fosse soltando prima inter pares» (una especie de gran estado federal), con más amplias miras geográficas que el de Pericles; tal imagen historiográfica, que se adentra en la historia ficción cuando «lascia validamente congetturare che, ottenuta la liberazione dal dominio spartano di tutte le poleis greche, anche con Sparta egli volesse instaurare buoni rapporti alla condizione che la libertà di quelle poleis greche fosse rispettata rigidamente» (pág. 519), acaba de recibir un espaldarazo de la mano de Marta Sordi (2000), quien considera que el pensamiento político de Trasibulo a lo largo de toda su carrera no estuvo condicionado exclusivamente por valores morales, sino por una profunda piedad religiosa canalizada a través de los misterios eleusinos (según Ciarfera 1991, la participación conjunta de oligarcas y demócratas atenienses en estos últimos favorecida por Trasibulo constituiría una llamada a la concordia entre ambos grupos para cerrar las heridas abiertas por el conflicto civil ateniense tras la guerra del Peloponeso). Véase también Kounas 1969: 97-99, 130 (un moderado que luego se desliza a la facción imperialista), Cawkwell 1976: 276 (imperialista desde 391); Funke 1980: 156; Strauss 1984: 153; Badian 1995: 85 (un antaño moderado Trasibulo «poseído por el viejo fantasma [del imperio] hasta el punto de ignorar la realidad»).

IIs Seager 1967: IIO-III y II5, donde acertadamente afirma que, a pesar de que Conón supo interpretar bien los sueños imperiales del pueblo ateniense, tenía las manos atadas por su lealtad al Rey para asumir y encabezar la empresa. También Corsaro 1994: 125-126 considera simplificadores y rígidos los retratos de un Conón radical y filopersa y de un Trasibulo moderado, antipersa y hasta para algunos ipacifista! (véase por ejemplo la definición de Cinzia Bearzot 1985: 107: «Un pacifismo [el de Andócides, Isócrates, Esquines] che appare ben diverso da quello di Trasibulo, uomo certo non estraneo agli ideali di giustizia e di pace e propugnatore di una politica di distensione internazionale, ma capace di non temer la guerra quand 'essa era giustificata dalla difesa della democrazia e dalla salvezza della città»). Sobre el intento de reconstrucción imperial ateniense encabezado por Trasibulo, véase ahora Fornis e.p. 


\section{Bibliografía}

ACCAME, S. 1951: Ricerche intorno alla guerra corinzia, Napoli.

— 1956: «Il problema della nazionalità greca nella politica di Pericle e Trasibulo», Paideia II, 24I-253 (reimpreso en Scritti Minori, III, Roma, 1990, 509-520, de donde se citan las páginas).

Alfieri Tonini, T. 1972: «L'ultima fase della carriera politica di Trasibulo», RIL I06, I22-I 48.

Alonso Troncoso, V. 1997: «Tratados y relaciones de alianza en la guerra de Corinto», RSA 27, 21-7I.

— 1999: «395-390/89 a.C., Atenas contra Esparta: ¿De qué guerra hablamos?», Athenaeum 87, 57-77

Anello, P. 1996: «Note sui rapporti tra Dionisio I e Atene nel primo decennio del IV secolo», Kókalos 42, 383-408.

Aucello, E. 1965: «La genesi della pace di Antalcida», Helikon 5, 340-380.

Badian, E. 1995: «The Ghost of Empire. Reflections on Athenian Foreign Policy in the Fourth Century B.C.», en W. Eder (Hrsg.), Die athenische Demokratie im 4. Jahrhundert v. Chr., Stuttgart, 79-106.

BARbieri, G. 1955: Conone, Roma.

BEARZOT, C. 1985: «Da Andocide ad Eschine: motivi e ambiguità del pacifismo ateniese nel IV secolo a.C.», en M. Sordi (a.c.), La pace nel mondo antico, CISA II, Milano, 86-107.

Beloch, K.J. 1884: Die attische Politik seit Perikles, Leipzig (hay edición anastática: Stuttgart, 1967).

- 1922: Griechische Geschichte, III, I, Berlin-Leipzig².

Besso, G. 1999: «L'azione politica in Atene all'inizio del IV secolo a.C.: gli "amici” di Conone», Quaderni Dip. Filol. Ling. Trad. Class. A. Rostagni 13, I15-129.

BiAnco, E. 1994: Atene «come il sole». L'imperialismo ateniese del V secolo a. C. nella storia e oratoria politica attica, Alessandria.

BrUCE, I.A.F. 1963: «Athenian Foreign Policy in 396-395 B.C.», CJ 58, 289-295.

— 1966: «Athenian Embassies in the Early Fourth Century», Historia 15, 272-28I.

Brun, P. 2005: Impérialisme et démocratie à Athènes. Inscriptions del l'époque classique (c. 500-317 av.J.-C.), Paris.

BUCK, R.J. 1994: Boeotia and the Boeotian League, 432-37I B.C., Edmonton.

- 1998: Thrasybulus and the Athenian Democracy. The Life of an Athenian Statesman, Historia Einzelschriften I20, Stuttgart.

BuCKLeR, J. 2004: Aegean Greece in the Fourth Century, Leiden.

CARTledge, P. 1979: Sparta and Lakonia. A Regional History 1300-362 B.C., London-Boston-Henley.

- 1987: Agesilaos and the Crisis of Sparta, Baltimore.

CAW KWELL, G.L. 1976: «The Imperialism of Thrasybulus», CQ26, 270-277.

CiARfer A, E. I991: «Lealtà democratica e pietà eleusinia di Trasibulo», en M. Sordi (a.c.), L'immagine dell'uomo politico: vita pubblica e morale nell antichità, CISA 17, Milano, 51-63.

Clark, M. 1990: « The Date of IG II2 I604 », BSA 85, 47-67.

CLOCHÉ, P. 1919: «Les conflits politiques et sociaux à Athènes pendant la guerre corinthienne (395-387 avant J.-C.)», REA 21, I57-192.

— 1934: La politique étrangère d'Athènes de 404 à 338 av. J.-C., Paris.

— I952: Thèbes de Béotie. Des origines à la conquête romaine, Namur.

— 1960: «Les hommes politiques et la justice populaire dans l'Athènes du IV siècle», Historia 9, 80-95.

Cook, M.L. 1981: Boeotia in the Corinthian War. Foreign Policy and Domestic Politics, Diss. Washington University. 
Corsaro, M. 1994: «Sulla politica estera persiana agli inizi del IV secolo: La Persia e Atene, 397-386 a.C.», en

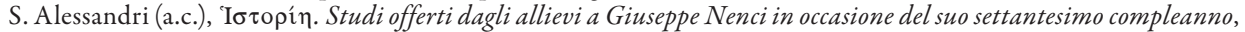
Galatina, 109-130.

Costa, E. 1974: «Evagoras I and the Persians, ca. 411-391 B.C.», Historia 23, 40-56.

Cox, C.A. 1998: Household Interests. Property, Marriage Strategies, and Family Dynamics in Ancient Athens, Princeton.

Culasso Gastaldi, E. 2004: Le prossenie ateniesi del IV secolo a.C. Gli Onorati asiatici, Alessandria.

Davies, J.K. 1971: Athenian Propertied Families 600-30o B.C., Oxford.

Debord, P. 1999: L'Asie Mineure au IV siècle (4I2-323 a.C.). Pouvoirs et jeux politiques, Bordeaux.

Develin, R. 1989: Athenian Officials 684-32I B.C., Cambridge.

Devoto, J.G. 1986: «Agesilaus, Antalcidas, and the Failed Peace of 392/1 B.C.», CPh 81, 191-202.

Dinsmoor, W.B. 1940: «The Tribal Cycles of the Treausurers of Athena», en Athenian Studies Presented to W.S. Ferguson, HSCPh Supp. I., Cambridge, 157-182.

Falkner, C. 1992: Sparta and the Sea. A History of Spartan Sea-Power, c. 706-c.373 B.C., Diss. University of Alberta.

Fernández Nieto, F.J. 1975: Los acuerdos bélicos en la antigua Grecia, II. Los instrumentos materiales de los convenios, Santiago de Compostela.

Fornis, C. 1999: Estabilidad y conflicto civil en la guerra del Peloponeso. Las sociedades corintia y argiva, BAR IS 762, Oxford.

- 2001: «Identidad corintia e identidad argiva en la 'unión' de 392-386 a.C.», en P. López Barja, S. Reboreda (eds.), Fronteras e identidad: III Reunión de Historiadores del Mundo Griego Antiguo, Santiago de Compostela-Vigo, 207-226.

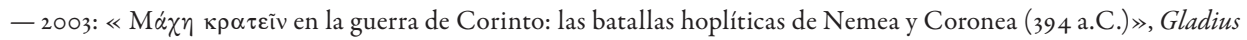
23, I4I-I59.

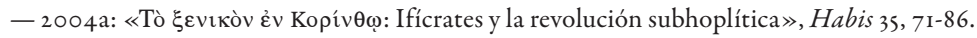

—2004b: «La guerra de Corinto (395-386 a.C.): una aproximación a las fuentes», Polifemo 4, 178-186.

-2005: «La imposible paz estable en la sociedad griega: ensayos de koiné eiréne durante la guerra de Corinto», SHHA 23, 269-292.

— 2006: «Identidad cultural y política de fuerza: los griegos asiáticos hasta la paz del Rey (386 a.C.)», en D. Plácido et alii (eds.), La construcción ideológica de la ciudadanía. Identidades culturales y sociedad en el mundo griego antiguo, Madrid, 283-30I.

- 2007a: «Las causas de la guerra de Corinto: un análisis tucidídeo», Gerión 25, 187-218.

— 2007b: «La conjura de Cinadón: ¿paradigma de resistencia de los dependientes lacedemonios?», en $X X X I$ Congreso del GIREA: Resistencia, sumisión e interiorización de la dependencia, SHHA 25, 103-115.

- e.p. «Trasibulo y el fracaso de la reconstrucción imperial ateniense en la guerra de Corinto», Klio 9i.I, en prensa.

Fornis C., Plácido D. e.p.: «De la guerra del Peloponeso a la paz del Rey: prosopografía política ateniense», $R S A 38$, en prensa.

Foss, C. 1974-75: «Greek Sling Bullets in Oxford», AR 21, 40-44.

Funke, P. 1980: Homónoia und Arché. Athen und die griechische Staatenwelt vom Ende des Peloponnesischen Krieges bis zum Königsfrieden (403-387/6 v. Chr.), Historia Einzelschriften 37, Wiesbaden.

— 1983: «Konons Rückkehr nach Athen im Spiegel epigraphischer Zeugnisse», ZPE 53, I49-189.

Garland, R. 1987: The Piraeus. From the Fifth to the First Century B.C., London.

GAUTHIER, P. 1985: Les cités grecques et leurs bienfaiteurs, BCH Suppl. XII, Paris.

$G H I=$ P.J. Rhodes, R. Osborne, Greek Historical Inscriptions 404-323 B.C., Oxford, 2003.

GiUliani, A. 1994: «Dionigi I, Sparta e la Grecia», RIL I28, I49-166.

$\mathrm{DH}_{34 / 2}-2008$ 
Griffith, G.T. 1978: «Athens in the Fourth Century», en P. Garnsey, C.R. Whittaker (edd.), Imperialism in the Ancient World, Cambridge, I27-I 44.

Hamel, D. 1998: Athenian Generals. Military Authority in the Classical Period, Mnemosyne Suppl. 182, Leiden.

Hamilton, C.D. 1979a: Sparta's Bitter Victories. Politics and Diplomacy in the Corinthian War, Ithaca-London.

— 1979b: «On the Perils of Extraordinary Honors: the Cases of Lysander and Conon», AncW 2, 87-90.

Harding, P. 1995: «Athenian Foreign Policy in the Fourth Century», Klio 77, 105-125.

Hofstetter, J. 1978: Die Griechen in Persien. Prosopographie der Griechen im Persischen Reich vor Alexander, Berlin.

$I G=$ Inscriptiones Graecae, Berlin, desde 1873 .

Jehne, M. 1991: «Die Friedensverhandlungen von Sparta 392/I v.Chr. und das Problem der kleinasiatischen Griechen», Chiron 21, 265-276.

JUdeICH, W. 1892: Kleinasiatische Studien. Untersuchungen zur griechisch-persischen Geschichte des IV Jahrbunderts v. Chr., Marburg.

Kounas, D.D.A. 1969: Prelude to Hegemony. Studies in Athenian Political Parties from 403 to 379 B.C. Pertaining to the Revival of Athenian Influence in Greece, Diss. University of Illinois.

Laing, D.R. 1965: A New Interpretation of the Athenian Naval Catalogue, IG II' I95I, Diss. University of Cincinnati.

LeW Is, D.M. 1977: Sparta and Persia, Leiden.

Lew IS, D.M., STroud, R.S. 1979: «Athens Honors King Euagoras of Salamis», Hesperia 48, 180-193.

Maffre, F. 2004: «Le monayage de Pharnabaze frappé dans l'atelier de Cyzique», NC 164, I-29.

March, D.A. 1997: «Konon and the Great King's Fleet, 396-394», Historia 46, 257-269.

Meloni, P. 1950: «Tiribazo, satrapo di Sardi», Athenaeum 28, 292-339.

Meyer, E. 1909: Theopomps Hellenica, Halle.

Mosley, D.J. 1973: «Conon's Embassy to Persia», RhM I16, 17-2I.

Osborne, M.J. 1970: «Honours for Sthorys $\left(I G \mathrm{II}^{2}\right.$. 17)», BSA 65, I5I-172.

- 1981: Naturalization in Athens, I, Brussels.

- 1982: Naturalization in Athens, II, Brussels.

PARETI, L. 1908-09: «Ricerche sulla potenza marittima degli Spartani e sulla cronologia dei nauarchi», MAT 59, 7I-I59 (reimpreso en Studi minori di storia antica, II: Storia greca, Roma, 1961, I-I3I).

Pascual González, J. I995: Tebas y la confederación beocia en el periodo de la guerra de Corinto (395-386 a.C.), Tesis Doctoral microfilmada, Universidad Autónoma de Madrid.

Pecorella Longo, C. 1971: "Eterie" e gruppipolitici nell'Atene del IV sec. a.C., Firenze.

Perlman, S. 1968: «Athenian Democracy and the Revival or Imperialistic Expansion at the Beginning of the Fourth Century B.C.», $C P h$ 63, 257-267.

— 1976: «On Bribing Athenian Ambassadors», GRBS 17, 223-233.

PiCCIRILli, L. 1973: Gli arbitrati interstatali greci, I: dalle origine al 338 a.C., Pisa.

Pritchett, W.K. 1974: The Greek State at War, Part II, Berkeley-Los Angeles-London.

RoBERT, L. 1934: «Diodore XIV,84,3», RPh 8, 43-48.

Ruzicka, S. 1997: «The Eastern Greek World», en L. Tritle (ed.), The Greek World in the Fourth Century, LondonNew York, 107-136.

Salmon, J.B. 1984: Wealthy Corinth. A History of the City to 338 B.C., Oxford.

SA DDERS, L.J. 1987: Dionysius I of Syracuse and Greek Tyranny, London. 
SARTORI, F. 1973: «Elementi storici del tardo teatro aristofanico e documentazione contemporanea», en Akten des VI. internationalen Kongresses für griechische und lateinische Epigraphik (München 1972), Vestigia 17, München, 327-343.

SAUR, L. 1978: Thrasybule de Stiria: une certaine idée d'Athènes, Diss. Université de Liège.

SEAGER, R. 1966: «Lysias against the Corn-Dealers», Historia 15, 172-184.

— 1967: «Thrasybulus, Conon and Athenian Imperialism 396-386 B.C.», JHS 87, 95 -115.

SEALEY, R. 1956: «Callistratos of Aphidna and his Contemporaries», Historia 5, 178-203.

Sensi Sestito, G. De 1979: «Correnti, leaders e politica estera in Atene (400-395)», Sic Gymn 32, I-42.

$S G H I=$ M.N. Tod, A Selection of Greek Historical Inscriptions, II. From 403 to 323 B.C., Oxford, 1948.

Singh K.L. 1971: The Impact of Family Relationships on Athenian Politics 594-322 B.C., Diss. University of Wisconsin.

Shrimpton, G.S. 1991: «Persian strategy against Egypt and the Date for the Battle of Citium», Phoenix 45, I-20.

$S I G=$ W. Dittenberger (ed.), Sylloge Inscriptionum Graecarum, Leipzig, 1915-19243.

SORDI, M. 2000: «Trasibulo tra politica e religione», RFIC I28, I82-19I.

STRauss, B.S. 1984: «Thrasybulus and Conon. A Rivalry in Athens in the 390s B.C.», AJPh 105, 37-48.

- 1985: «The Cultural Significance of Bribery and Embezzlement in Athenian Politics: The Evidence of the Period 403-386 B.C.», AncW II, 67-74.

- 1986: Athens after the Peloponnesian War. Class, Faction and Policy, 403-386 B.C., London.

Treves, P. 1937: «Note sulla guerra corinzia», RFIC I5, I13-1 40 y $278-283$.

Tuplin, C. 1993: The Failings of Empire. A Reading of Xenophon Hellenica 2.3.1I-7.5.27, Historia Einzelschriften 76, Stuttgart.

URban, R. 1991: Der Königsfrieden von $387 / 6$ v. Chr. Vorgeschichte, Zustadekommen, Ergebnis und politische Umsetzung, Historia Einzelschriften 68, Stuttgart.

Wilamowitz-Moellendorff, U. von 1921: «Friedensverhandlungen 392 und 391», SB Akad. Berlin 2I, 735-738.

WoodheAD, A.G. 1948: «Greek Inscriptions», Hesperia 17, 54-60. 